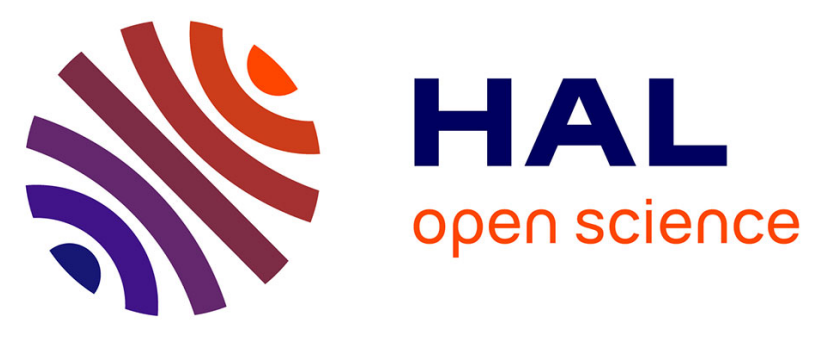

\title{
InterCarb: A Community Effort to Improve Interlaboratory Standardization of the Carbonate Clumped Isotope Thermometer Using Carbonate Standards
}

Stefano M. Bernasconi, Mathieu Daëron, Kristin D. Bergmann, Magali Bonifacie, Anna Nele Meckler, Hagit P. Affek, Noah T. Anderson, David Bajnai, Eugeni S. Barkan, Emily J. Beverly, et al.

\section{- To cite this version:}

Stefano M. Bernasconi, Mathieu Daëron, Kristin D. Bergmann, Magali Bonifacie, Anna Nele Meckler, et al.. InterCarb: A Community Effort to Improve Interlaboratory Standardization of the Carbonate Clumped Isotope Thermometer Using Carbonate Standards. Geochemistry, Geophysics, Geosystems, 2021, 22 (5), 10.1029/2020GC009588 . hal-03256441

\author{
HAL Id: hal-03256441 \\ https://hal.science/hal-03256441
}

Submitted on 10 Jun 2021

HAL is a multi-disciplinary open access archive for the deposit and dissemination of scientific research documents, whether they are published or not. The documents may come from teaching and research institutions in France or abroad, or from public or private research centers.
L'archive ouverte pluridisciplinaire HAL, est destinée au dépôt et à la diffusion de documents scientifiques de niveau recherche, publiés ou non, émanant des établissements d'enseignement et de recherche français ou étrangers, des laboratoires publics ou privés.

\section{(ㄷ)(1) $\$$}

Distributed under a Creative Commons Attribution - NonCommerciall 4.0 International 


\section{Geochemistry, Geophysics, Geosystems}

\author{
RESEARCH ARTICLE \\ 10.1029/2020GC009588 \\ Special Section: \\ Clumped Isotope Geo- \\ chemistry: From Theory to \\ Applications
}

This article is a companion to Daëron (2021), https://doi.org/10.1029/ 2020GC009592.

Key Points:

- The exclusive use of carbonate reference materials is a robust method for the standardization of clumped isotope measurements

- Measurements using different acid temperatures, designs of preparation lines, and mass spectrometers are statistically indistinguishable

- We propose new consensus values for a set of seven carbonate reference materials and updated guidelines to report clumped isotope measurements

Supporting Information: Supporting Information may be found in the online version of this article.

Correspondence to:

S. M. Bernasconi and M. Daëron, stefano.bernasconi@erdw.ethz.ch; daeron@lsce.ipsl.fr

\section{Citation:}

Bernasconi, S. M., Daëron, M., Bergmann, K. D., Bonifacie, M., Meckler, A. N., Affek, H. P., et al. (2021). InterCarb: A community effort to improve interlaboratory standardization of the carbonate clumped isotope thermometer using carbonate standards. Geochemistry, Geophysics, Geosystems, 22, e2020GC009588. https://doi. org/10.1029/2020GC009588

\section{(c) 2021. The Authors.}

This is an open access article under the terms of the Creative Commons Attribution-NonCommercial License, which permits use, distribution and reproduction in any medium, provided the original work is properly cited and is not used for commercial purposes.

\section{InterCarb: A Community Effort to Improve Interlaboratory Standardization of the Carbonate Clumped Isotope Thermometer Using Carbonate Standards}

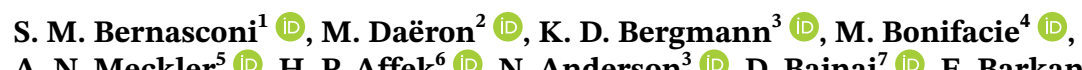
A. N. Meckler $^{5}$ (D) H. P. Affek ${ }^{6}$ (D) N. Anderson ${ }^{3}$ (D) D. Bajnai ${ }^{7}$ (D) E. Barkan ${ }^{6}$, E. Beverly ${ }^{8,9}$ (D), D. Blamart ${ }^{2}$, L. Burgener ${ }^{10}$ (D) D. Calmels ${ }^{4,11}$, C. Chaduteau ${ }^{4}$, M. Clog $^{12}$ (D), B. Davidheiser-Kroll ${ }^{13}$, A. Davies ${ }^{14,21}$, F. Dux ${ }^{15,34}$, J. Eiler $^{16}$, B. Elliott $^{17}$, A. C. Fetrow ${ }^{13}$ (D),

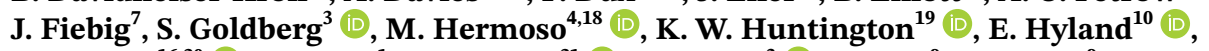
M. Ingalls ${ }^{16,20}$ (D), M. Jaggi ${ }^{1}$, C. M. John ${ }^{21}$ (D) A. B. Jost ${ }^{3}$ (D), S. Katz', J. Kelson', T. Kluge ${ }^{21,22}$, I. J. Kocken ${ }^{23}$ (D) A. Laskar ${ }^{24}$ (D), T. J. Leutert ${ }^{5,25}$ (D), D. Liang ${ }^{24}$, J. Lucarelli ${ }^{17}$ (D), T. J. Mackey,26 (D) X. Mangenot ${ }^{4,16}$, N. Meinicke ${ }^{5}$ (D) S. E. Modestou ${ }^{5}$ (D), I. A. Müller ${ }^{23}$ (D), S. Murray $^{27}$, A. Neary ${ }^{9}$, N. Packard ${ }^{9}$, B. H. Passey ${ }^{9}$, E. Pelletier ${ }^{9}$, S. Petersen ${ }^{9}$ (D) A. Piasecki ${ }^{5,28}$,

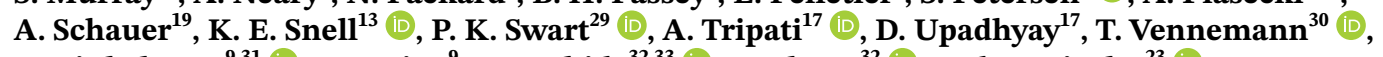
I. Winkelstern ${ }^{9,31}$ (D), D. Yarian', N. Yoshida ${ }^{32,33}$ (D), N. Zhang ${ }^{32}$ (D) , and M. Ziegler ${ }^{23}$ (D)

${ }^{1}$ Geological Institute, ETH Zürich, Zürich, Switzerland, ${ }^{2}$ Laboratoire des Sciences du Climat et de l'Environnement, LSCE/IPSL, CEA-CNRS-UVSQ, Université Paris-Saclay, Gif-sur-Yvette, France, ${ }^{3}$ Department of Earth, Atmospheric and Planetary Sciences, Massachusetts Institute of Technology, Cambridge, MA, USA, ${ }^{4}$ Université de Paris, Institut de Physique du Globe de Paris, CNRS, Paris, France, ${ }^{5}$ Bjerknes Centre for Climate Research and Department of Earth Science, University of Bergen, Bergen, Norway, ${ }^{6}$ Institute of Earth Sciences, Hebrew University of Jerusalem, Jerusalem, Israel, ${ }^{7}$ Institute of Geosciences, Goethe University Frankfurt, Frankfurt am Main, Germany, ${ }^{8}$ Now at Department of Earth and Atmospheric Sciences, University of Houston, Houston, TX, USA, ${ }^{9}$ Department of Earth and Environmental Sciences, University of Michigan, Ann Arbor, MI, USA, ${ }^{10}$ Department of Marine, Earth and Atmospheric Sciences, North Carolina State University, Raleigh, NC, USA, ${ }^{11}$ Now at Geosciences Paris Sud (GEOPS), Université Paris-Saclay, CNRS, Orsay, France, ${ }^{12}$ Scottish Universities Environmental Research Centre (SUERC), Scotland, UK, ${ }^{13}$ University of Colorado Boulder, Boulder, CO, USA, ${ }^{14}$ Now at Stockholm University, Stockholm, Sweden, ${ }^{15}$ Now at School of Earth and Life Sciences, University of Wollongong, Wollongong, Australia, ${ }^{16}$ Geological and Planetary Sciences, California Institute of Technology, Pasadena, CA, USA, ${ }^{17}$ Department of Earth, Planetary, and Space Sciences, University of California Los Angeles, Los Angeles, CA, USA, ${ }^{18}$ Univ. Littoral Côte d’Opale, Univ. Lille, CNRS, Laboratoire d'Océanologie et de Géosciences (UMR 8187 LOG), Wimereux, France, ${ }^{19}$ University of Washington, Seattle, WA, USA, ${ }^{20}$ Now at Department of Geosciences, The Pennsylvania State University, University Park, PA, USA, ${ }^{21}$ Imperial College, London, UK, ${ }^{22}$ Now at Karlsruher Institut für Technologie KIT, Karlsruhe, Germany, ${ }^{23}$ Department of Earth Sciences, University of Utrecht, Utrecht, The Netherlands, ${ }^{24}$ Institute of Earth Sciences, Academia Sinica, Taipei, Taiwan, ${ }^{25}$ Now at Max Planck Institute for Chemistry, Mainz, Germany, ${ }^{26}$ Now at Department of Earth and Planetary Sciences, University of New Mexico, Albuquerque, NM, USA, ${ }^{27}$ Macquarie University, Sydney, Australia, ${ }^{28}$ Now at Department of Earth Sciences, Dartmouth College, Hanover, NH, USA, ${ }^{29}$ Department of Marine Geosciences, Rostiel School of Marine and Atmospheric Sciences, University of Miami, Miami, FL, USA, ${ }^{30}$ Institute of Earth Surface Dynamics, University of Lausanne, Lausanne, Switzerland, ${ }^{31}$ Now at Geology Department, Grand Valley State University, Allendale, MI, USA, ${ }^{32}$ Earth-Life Science Institute, Tokyo Institute of Technology, Tokyo, Japan, ${ }^{33}$ National Institute of Information and Communications Technology, Tokyo, Japan, ${ }^{34}$ School of Geography, University of Melbourne, Melbourne, Australia

Abstract Increased use and improved methodology of carbonate clumped isotope thermometry has greatly enhanced our ability to interrogate a suite of Earth-system processes. However, interlaboratory discrepancies in quantifying carbonate clumped isotope $\left(\Delta_{47}\right)$ measurements persist, and their specific sources remain unclear. To address interlaboratory differences, we first provide consensus values from the clumped isotope community for four carbonate standards relative to heated and equilibrated gases with 1,819 individual analyses from 10 laboratories. Then we analyzed the four carbonate standards along with three additional standards, spanning a broad range of $\delta^{47}$ and $\Delta_{47}$ values, for a total of 5,329 analyses on 25 individual mass spectrometers from 22 different laboratories. Treating three of the materials as known standards and the other four as unknowns, we find that the use of carbonate reference materials 
Received 11 DEC 2020

Accepted 19 MAR 2021

Author Contributions:

Conceptualization: S. M. Bernasconi,

M. Daëron, K. D. Bergmann, M.

Bonifacie, A. N. Meckler

Data curation: M. Daëron

Formal analysis: S. M. Bernasconi, M.

Daëron, K. D. Bergmann, M. Bonifacie, A. N. Meckler

Investigation: S. M. Bernasconi,

M. Daëron, K. D. Bergmann, M.

Bonifacie, A. N. Meckler, H. P. Affek,

N. Anderson, D. Bajnai, E. Barkan,

E. Beverly, D. Blamart, L. Burgener,

D. Calmels, C. Chaduteau, M. Clog,

B. Davidheiser-Kroll, A. Davies, F.

Dux, J. Eiler, B. Elliott, A. C. Fetrow, J.

Fiebig, S. Goldberg, M. Hermoso, K. W. Huntington, E. Hyland, M. Ingalls, M.

Jaggi, C. M. John, A. B. Jost, S. Katz, J.

Kelson, T. Kluge, I. J. Kocken, A. Laskar,

T. J. Leutert, D. Liang, J. Lucarelli, T. J.

Mackey, X. Mangenot, N. Meinicke, S.

E. Modestou, I. A. Müller, S. Murray,

A. Neary, N. Packard, B. H. Passey, E.

Pelletier, S. Petersen, S. Petersen, A.

Piasecki, A. Schauer, K. E. Snell, P.

K. Swart, A. Tripati, D. Upadhyay, T.

Vennemann, I. Winkelstern, D. Yarian, N. Yoshida

Methodology: S. M. Bernasconi, M.

Daëron, K. D. Bergmann, M. Bonifacie, A. N. Meckler

Software: M. Daëron

Writing - original draft: S. M.

Bernasconi, M. Daëron, K. D.

Bergmann, M. Bonifacie, A. N. Meckler

Writing - review \& editing: $S$.

M. Bernasconi, M. Daëron, K. D.

Bergmann, M. Bonifacie, A. N. Meckler,

H. P. Affek, N. Anderson, D. Bajnai,

E. Barkan, E. Beverly, D. Blamart, L.

Burgener, D. Calmels, C. Chaduteau, M.

Clog, B. Davidheiser-Kroll, A. Davies, F.

Dux, J. Eiler, B. Elliott, A. C. Fetrow, J.

Fiebig, S. Goldberg, M. Hermoso, K. W.

Huntington, E. Hyland, M. Ingalls, M.

Jaggi, C. M. John, A. B. Jost, S. Katz, J.

Kelson, T. Kluge, I. J. Kocken, A. Laskar,

T. J. Leutert, D. Liang, J. Lucarelli, T. J.

Mackey, X. Mangenot, N. Meinicke, S.

E. Modestou, I. A. Müller, S. Murray,

A. Neary, N. Packard, B. H. Passey, E.

Pelletier, S. Petersen, S. Petersen, A.

Piasecki, A. Schauer, K. E. Snell, P.

K. Swart, A. Tripati, D. Upadhyay, T.

Vennemann, I. Winkelstern, D. Yarian,

N. Yoshida is a robust method for standardization that yields interlaboratory discrepancies entirely consistent with intralaboratory analytical uncertainties. Carbonate reference materials, along with measurement and data processing practices described herein, provide the carbonate clumped isotope community with a robust approach to achieve interlaboratory agreement as we continue to use and improve this powerful geochemical tool. We propose that carbonate clumped isotope data normalized to the carbonate reference materials described in this publication should be reported as $\Delta_{47}$ (I-CDES) values for Intercarb-Carbon Dioxide Equilibrium Scale.

\section{Introduction}

Carbonate clumped isotope $\left(\Delta_{47}\right)$ thermometry is the most developed branch of the rapidly evolving field of clumped isotope geochemistry. Given the broad range of applications in Earth Sciences (e.g., Affek \& Eiler, 2006; Dale et al., 2014; Eagle et al., 2010; Ferry et al., 2011; Ghosh, Adkins, et al., 2006; Ghosh, Garzione, \& Eiler, 2006; Grauel et al., 2013; Guo \& Eiler, 2007; Huntington et al., 2011; Mangenot et al., 2018; Passey \& Henkes, 2012; Veillard et al., 2019) and the improvement of analytical methods including automation (Adlan et al., 2020; Bernasconi et al., 2018, 2013; Defliese \& Lohmann, 2015; Dennis et al., 2011; Fiebig et al., 2019; Ghosh, Adkins, et al., 2006; He et al., 2012; Hu et al., 2014; Huntington et al., 2009; Meckler et al., 2014; Müller, Fernandez, et al., 2017; Passey et al., 2010; Petersen et al., 2016, 2019; Schmid \& Bernasconi, 2010), the last 5-10 years have seen an increasing number of laboratories implementing this technique. The great potential of this thermometer can only be fully exploited if precision and accuracy are sufficient to resolve differences of a few degrees in formation temperatures. In addition, widely available reference materials that match the sample matrices are necessary so that data can be robustly compared across laboratories (Meier-Augenstein \& Schimmelmann, 2019). Currently the situation in the field of carbonate clumped isotope geochemistry is far from satisfactory. Published values for the ETH reference materials, the only carbonates that have been recently measured in many different laboratories worldwide, differ by up to 0.053\%o (see Bernasconi et al., 2018; Thaler et al., 2020 for recent comparisons). For paleoclimate applications, however, a repeatability across laboratories of $0.01 \%$ or better is a necessary goal for meaningful data comparison. This clearly calls for better standardization procedures to improve laboratory comparability.

The data normalization scheme currently used in clumped isotope geochemistry of carbonates in many laboratories is based on the comparison of the composition of the $\mathrm{CO}_{2}$ liberated from carbonates by reaction with phosphoric acid with that of a set of $\mathrm{CO}_{2}$ gases with different bulk and clumped isotope compositions (Dennis et al., 2011). These gases are prepared either by heating $\mathrm{CO}_{2}$ at $1000^{\circ} \mathrm{C}$ (heated gases; $\mathrm{HG}$ ) or by $\mathrm{CO}_{2}$ equilibration with water at low temperatures (equilibrated gases at e.g., $25^{\circ} \mathrm{C}, 50{ }^{\circ} \mathrm{C}$; EG). By comparing the measured compositions with the theoretical predictions of the equilibrium thermodynamic abundance of multiply substituted isotopologues in heated and equilibrated gases (Wang et al., 2004; and updates in Petersen et al., 2019), the measurements are standardized to the scale that was named the "absolute reference frame" (ARF) by Dennis et al. (2011). In more recent publications, the ARF is often referred to as the "Carbon Dioxide Equilibration Scale" (CDES), a terminology introduced by Passey and Henkes (2012). This approach was designed to allow different laboratories to link their measurements to an internationally recognized scale firmly anchored to theory using relatively easy and established laboratory protocols to produce $\mathrm{CO}_{2}$ standard gases of known isotopic composition. Early comparisons of $\Delta_{47} \mathrm{CDES}$ values for carbonates analyzed in different laboratories and corrected with HG/EG normalization were promising (Dennis et al., 2011). While Bonifacie et al. (2017) reported similar $\Delta_{47}$ CDES values for nine dolomite samples covering a range of almost $0.4 \%$ measured both at Caltech and IPGP laboratories with HG/EG normalization, Spooner et al. (2016) found that carbonate standardization improved agreement between data they obtained on samples analyzed both at Caltech and WHOI laboratories, compared to when they were using HG/EG normalization. Such recurrent cases of poor interlaboratory reproducibility (see also Bernasconi et al., 2018; Thaler et al., 2020) suggest that there are still unexplained differences in the results among laboratories (see Petersen et al., 2019 for a recent review).

Apart from preservation problems, two known issues still limiting the reliability of this method to yield accurate temperature reconstructions are: (1) the lack of internationally recognized carbonate reference materials for a precise interlaboratory calibration, and (2) that published $\Delta_{47}$-temperature calibrations produced in different laboratories have differed in both temperature dependence (slope) and absolute value 
(intercept). Possible reasons for the differences in slopes and intercepts of the $\Delta_{47}$ temperature dependence have been widely discussed in the literature (e.g., Bonifacie et al., 2017; Daëron et al., 2016; Fernandez et al., 2017; Katz et al., 2017; Kelson et al., 2017; Kluge et al., 2015; Petersen et al., 2019; Schauer et al., 2016). Discrepancies have been attributed to analytical artifacts such as $\mathrm{CO}_{2}$-acid re-equilibration at different acid digestion temperatures (see Swart et al., 2019; Wacker et al., 2013, for a recent discussion) and to slight pressure imbalances between sample and reference gas (Fiebig et al., 2016). Other factors proposed to influence the calculated slopes of the calibrations are the limitations of the data sets used in the individual studies, in particular in terms of the number of samples and replicates and of the temperature range covered by the available samples (Bonifacie et al., 2017; Fernandez et al., 2017). However, the discrepancies in the intercepts of the calibrations, for example, between Kelson et al. (2017) and Peral et al. (2018), and a generally poor laboratory comparability remain problems that could be mitigated by using a more robust standardization method.

Petersen et al. (2019), in a recent effort to resolve differences in calibrations, compiled raw data of a number of published temperature calibrations and recalculated them all in a consistent way using the revised IUPAC correction parameters to correct for the ${ }^{17} \mathrm{O}$ abundance (Daëron et al., 2016; Schauer et al., 2016). The goal was to test whether data processing differences and/or the use of consistent but incorrect ${ }^{17} \mathrm{O}$-correction parameters in the calculations were the root causes of inconsistencies. The result of this study was that differences among calibrations were reduced but not eliminated by the recalculation, implying that other factors must be responsible for the remaining discrepancies. These differences have pushed many laboratories to use laboratory-specific calibrations performed with the same analytical approach, as they at least partially take into consideration possible procedural differences (Petersen et al., 2019). However, if a laboratory changes analytical procedures or has not generated a robust in-house calibration, this approach is problematic. Achieving an interlaboratory reproducibility at the level of accuracy necessary for meaningful interpretations of the observed variations is a requirement for $\Delta_{47}$ thermometry to reach its potential as a mature analytical method with broad acceptance and quantitative usefulness.

While the definition of the CDES was a major milestone (Dennis et al., 2011), a known problem with this approach is that while the $\mathrm{CO}_{2}$ standard gases equilibrated at known temperature (HG or EG) can be confidently used for correction of mass spectrometric fractionations/nonlinearities and for effects of the purification procedures, they cannot account for the effects of the phosphoric acid reaction on the composition of the produced $\mathrm{CO}_{2}$. Among the factors responsible for discrepant calibrations and laboratory comparability, two important ones cannot be tested with a gas-based standardization: (1) the absolute value and temperature dependence of the phosphoric acid fractionation factor (see Petersen et al., 2019 for a recent compilation) and (2) possible $\mathrm{CO}_{2}$ equilibration effects during acid digestion of the sample. Swart et al. (2019) presented evidence that equilibration of $\mathrm{CO}_{2}$ with water or hot metal surfaces during phosphoric acid reaction and transfer of the $\mathrm{CO}_{2}$ to the mass spectrometer could be a factor leading to the alteration of the apparent temperature dependence of clumped isotopes in carbonates and on the absolute value of calculated $\Delta_{47}$. As many laboratories use custom built extraction lines with different designs and volumes of tubing and of acid vessels, these factors are impossible to precisely quantify for each laboratory and may further contribute to interlaboratory discrepancies.

We propose that these issues can be circumvented if carbonates, which undergo the same acid digestion as the samples, are used for normalization instead of or in addition to gases, consistent with the principle of identical treatment of sample and standards (Carter \& Fry, 2013; Werner \& Brand, 2001). In addition, normalizing results to accepted carbonate reference material values, as is commonly done with conventional carbon and oxygen isotope analysis in carbonates, removes the requirement to precisely quantify acid fractionation factors at different temperatures (Bernasconi et al., 2018).

A carbonate standardization approach was introduced by Schmid and Bernasconi (2010) and improved by Meckler et al. (2014), with the following benefits: (1) the use of carbonates can more easily be fully automated, eliminating time-consuming and possibly error-prone manual preparation of $\mathrm{CO}_{2}$ standard gases (equilibrated at known temperature) by individual users on separate extraction lines; (2) in some automated systems designed for the measurement of small carbonate samples (e.g., the Kiel Device), the heated and equilibrated gases had to be measured through a different capillary than the gases produced by acid digestion of carbonates with potential biases that would go unrecognized; and (3) in these same systems 
the equilibrated and heated gases are measured at constant ion beam intensity in bellow mode, whereas the samples are measured with decreasing ion beams in microvolume mode. These features argue in favor of carbonate standardization a priori, but it remains critical to assess a posteriori whether the results of this approach are as robust and accurate as expected and whether they significantly improve the interlaboratory reproducibility of $\Delta_{47}$ measurements. Discussions at the Sixth International Clumped Isotope Workshop in Paris in 2017 led to the present interlaboratory comparison exercise (InterCarb) to evaluate the benefits and drawbacks of a carbonate-based standardization approach as an alternative to the use of gas standards.

The primary goal of this study was to test whether the exclusive use of carbonate reference materials as a substitute for heated and equilibrated gases can minimize interlaboratory discrepancies and provide an alternative to the measurement of heated and equilibrated gases for the entire community. This is particularly important because of the increasing number of laboratories using commercial small-sample automated devices which cannot easily be standardized using the HG-EG approach. The InterCarb exercise also provides an opportunity to define the best community-derived consensus $\Delta_{47}$ values for the ETH standards of Meckler et al. (2014). Although these standards are already used in many laboratories, their current nominal $\Delta_{47}$ values are based on measurements from the ETH laboratory only. The InterCarb exercise can similarly establish community accepted values for other common carbonate reference materials, some of which have been in use for several years, in order to provide the community with a self-consistent set of carbonate reference materials with a broad range of bulk and clumped isotope compositions.

\subsection{Nomenclature and Data Processing}

Clumped isotope compositions are reported as an excess abundance of the $\mathrm{CO}_{2}$ isotopologue of cardinal mass 47 (dominantly the isotopologues ${ }^{13} \mathrm{C}^{18} \mathrm{O}^{16} \mathrm{O}$ ) compared to a stochastic distribution according to the formula:

$$
\Delta_{47}=R^{47} / R^{47^{*}}-1
$$

where $R^{47}$ is the ratio of the abundances of the set of minor isotopologues with mass 47 (mostly ${ }^{13} \mathrm{C}^{18} \mathrm{O}^{16} \mathrm{O}$ and trace amounts of ${ }^{12} \mathrm{C}^{17} \mathrm{O}^{18} \mathrm{O}$ and ${ }^{13} \mathrm{C}^{17} \mathrm{O}_{2}$ ) divided by the abundance of the most abundant isotopologue with mass $44\left({ }^{12} \mathrm{C}^{16} \mathrm{O}_{2}\right)$. The stochastic ratio $R^{47^{*}}$ is calculated using the measured abundance of ${ }^{13} \mathrm{C}$ and ${ }^{18} \mathrm{O}$ and measured or calculated abundance of $17 \mathrm{O}$ in the sample (Affek \& Eiler, 2006). According to the IUPAC guidelines the formula does not include the factor 1,000 (Coplen, 2011; though $\Delta_{47}$ is commonly reported in units of per mil, which implies multiplication by a factor of 1,000). Also, we omit here the classically included terms involving $R^{45_{*}}$ and $R^{46 *}$, which are assumed to be zero by definition when computing $\delta^{13} \mathrm{C}$ and $\delta^{18} \mathrm{O}$, and in practice never exceed $\pm 0.00002 \%$ in our calculations (Daëron et al., 2016). The measured abundance of isotopologues with $\mathrm{m} / \mathrm{z} 47$ in the sample with respect to the working gas (WG) in the mass spectrometer is reported in the traditional delta notation as:

$$
\delta^{47}=R^{47} / R_{\mathrm{WG}}^{47}-1
$$

The $\delta^{47}$ scale is a measure of the difference between the sample of interest and the WG of the specific instrument, therefore, it cannot be compared across laboratories. The same notation is used for masses 45 , 46,48 , and 49.

The $\mathrm{CO}_{2}$ gas-based standardization scheme for clumped isotope thermometry in carbonates relies on a set of $\mathrm{CO}_{2}$ standard gases with different bulk compositions $\left(\delta^{13} \mathrm{C}\right.$ and $\delta^{18} \mathrm{O}$, leading to different $\left.\delta^{47}\right)$, preferably chosen by the user to encompass the $\delta^{47}$ values of unknown samples that have been (1) heated at $1000{ }^{\circ} \mathrm{C}$ to reach a near-stochastic distribution of all isotopologues, or (2) equilibrated with water at low temperature to reach equilibrium enrichments in the mass-47 isotopologues (Dennis et al., 2011). The heated gases, having a near-stochastic distribution of the heavy isotopes among all isotopologues, define the zero point of the CDES scale, through the assumption that at $1000{ }^{\circ} \mathrm{C}$ these gases achieve a $\Delta_{47}=0.0266 \%$, and the water-equilibrated gases define a second, generally higher point on this scale (e.g., at $25^{\circ} \mathrm{C} \Delta_{47}=0.9196 \%$ ) . The theoretical values linking measurements to theory were calculated by Wang et al. (2004) and revised 


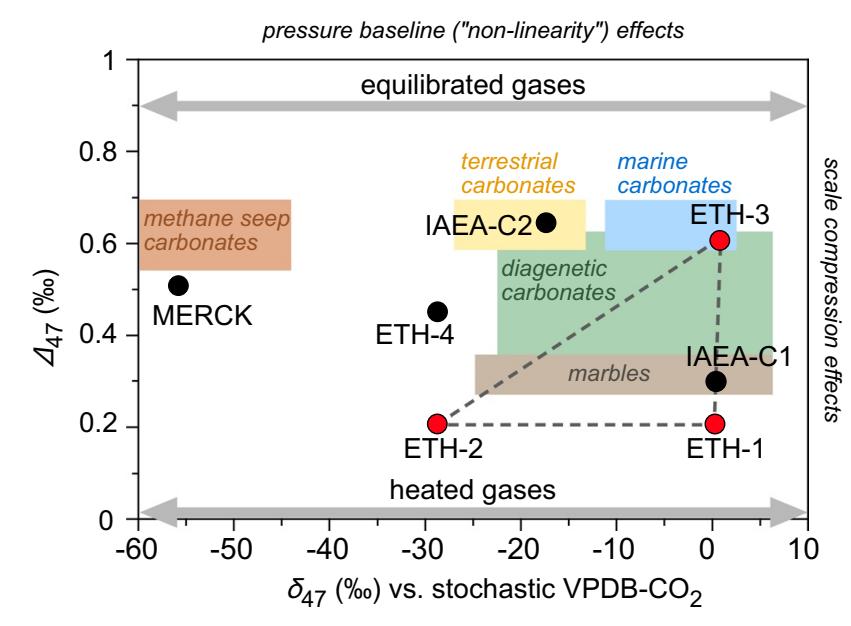

Figure 1. The $\delta_{47}$ versus $\Delta_{47}$ values of carbonate standards $\left(\Delta_{47}\right.$ on the I-CDES scale proposed here) and heated and equilibrated gases in comparison to the compositional ranges of typical natural carbonates. The observed range in measured clumped isotope compositions in natural carbonates can be completely bracketed by heated and equilibrated $\mathrm{CO}_{2}$ standard gases from which $\delta_{47}$ values have been chosen by the user. The $\delta_{47}$ values for the anchor samples used in InterCarb (red) and the unknowns (black) are reported for a theoretical working gas with stochastic isotope distribution, derived from VPDB. Actual $\delta_{47}$ values will vary by laboratory depending on the composition of the working gas. Note the smaller achievable range in both $\delta_{47}$ and $\Delta_{47}$ values when using carbonate standards compared to heated and equilibrated gases and the large extrapolation necessary for the determination of the composition for MERCK. Heated and equilibrated $\mathrm{CO}_{2}$ standard gases have a larger $\Delta_{47}$ range, allowing for more robust stretching calculations with identical numbers of standard:sample analyses. I-CDES, Intercarb-Carbon Dioxide Equilibrium Scale. by Petersen et al. (2019). A wide range in $\delta^{47}$ values of gases used for normalization is generally chosen to allow for accurate correction for an apparent dependence of $\Delta_{47}$ on $\delta^{47}$, which is caused by inaccurate pressure-dependent background corrections on the $\mathrm{m} / \mathrm{z} 47$ collector observed on many instruments (Bernasconi et al., 2013; He et al., 2012). The large range in $\Delta_{47}$ (i.e., $25^{\circ} \mathrm{C}, 1000{ }^{\circ} \mathrm{C}$ ), on the other hand, is necessary to correct for scale compression caused by processes of scrambling and molecule recombination in the source of the mass spectrometer or elsewhere in the sample preparation, transfer lines and/or the capillaries (Dennis et al., 2011; Swart et al., 2019). With properly chosen $\mathrm{CO}_{2}$ standard gases with widely varying $\delta^{47}$ values it is possible to cover the entire range of natural carbonate compositions, avoiding extrapolations in the $\delta^{47}$ versus $\Delta_{47}$ compositional space (Figure 1). Note that with measurement errors (typically no better than $0.010 \%$ ) being relatively large compared to the natural compositional range (less than $0.5 \%$; Figure 1$)$, the large $(0.9 \%$ o difference in $\Delta_{47}$ of the $\mathrm{CO}_{2}$ standard gases minimizes errors introduced by uncertainties resulting from the measurement of HG and EG.

Meckler et al. (2014) attempted to achieve a similar framework as the $\mathrm{CO}_{2}$ gas-based standardization but with carbonate standards. They described four carbonates that were developed at ETH Zürich to serve as replacements for HG's and EG's and demonstrated that good long- and short-term reproducibility can be achieved using only carbonates for data correction. Bernasconi et al. (2018) discussed in detail these standards and postulated, based on a limited interlaboratory data set, that carbonate standardization should generally improve interlaboratory data comparability. This claim seems arguably strengthened by the results of Meinicke et al. (2020), Peral et al. (2018), Piasecki et al. (2019), Kele et al. (2015) as recalculated by Bernasconi et al. (2018), and Jautzy et al. (2020). The first three studies produced independent foraminifera-based the fourth a travertine and the fifth a synthetic carbonate-based $\Delta_{47}$-temperature calibration anchored to the same set of carbonate standards. These studies yielded statistically indistinguishable slopes and intercepts despite the use of independent sample sets and in the case of Peral et al. (2018), a different analytical system. In addition, a reanalysis of samples from five previous calibrations by Anderson et al. (2021) using carbonate standardization revealed no significant differences in temperature dependence of $\Delta_{47}$ between the different sample sets. This, solved a long standing debate about variations in slope among calibrations

A possible limitation of carbonate standardization is that available carbonates have a smaller range in $\delta^{47}$ and, perhaps more importantly, a smaller range in $\Delta_{47}$ values than what is achievable with heated and equilibrated gases. In some specific cases, standardization procedures require extrapolation to compositions that are not within the $\delta^{47}-\Delta_{47}$ space created by carbonate standards (Figure 1). In addition, the range of $\Delta_{47}$ values for carbonates is only on the order of $0.5 \%$ o between 0 and $1000{ }^{\circ} \mathrm{C}$. The smaller range in $\Delta_{47} \mathrm{com}-$ pared to HG's and EG's requires higher precision and also a larger number of replicates of both standards and samples. Daëron (2021) and Kocken et al. (2019) suggest 50:50 ratio of standard to sample replicates to keep standardization errors small.

\subsection{InterCarb Goals and Design}

InterCarb was designed with the aim to carefully evaluate the potential of carbonates to serve as a standardization scheme that improves interlaboratory agreement for "unknown" carbonates both inside and outside of the $\delta^{47}-\Delta_{47}$ space defined by the anchor samples (Figure 2). The main questions posed are:

1. Is it possible to produce consistent carbonate clumped isotope measurements across laboratories using carbonate reference materials exclusively? In other words, does the observed interlaboratory scatter in $\Delta_{47}$ values match that expected from intralaboratory analytical precision? 
2. How well does the carbonate standardization approach perform when extrapolating beyond the $\delta^{47}-\Delta_{47}$ compositional space sampled by a set of carbonate reference materials?

3. Do carbonate reference materials fully correct effects arising from different reaction temperatures, sample preparation protocols, and analytical equipment?

4. Can we define a self-consistent set of widely available reference materials with community-agreed compositions accurately anchored to the CDES scale?

5. Does the use of carbonate reference materials for standardization improve the interlaboratory reproducibility compared to using HG's and EG's?

\subsection{Approach}

Seven carbonate standards with a large range of $\delta^{47}$ and $\Delta_{47}$ values (Figure 1) were distributed among participating laboratories and analyzed, treating three carbonates as "anchors" (whose $\Delta_{47}$ values are assigned a priori) and the remaining four as "unknowns" (whose $\Delta_{47}$ values are unknown, to be determined by comparison with the anchors). Due to their relatively widespread use in different laboratories, the three reference materials ETH-1, ETH-2, and ETH-3 (Bernasconi et al., 2018; Meckler et al., 2014) were chosen as anchors. They are still available today in relatively large quantities ( $>600 \mathrm{~g})$, have been in use at ETH since 2013 and in many other laboratories for several years. Importantly, they have been thoroughly tested for homogeneity based on thousands of measurements in 80-150 $\mu \mathrm{g}$ aliquot sizes in different laboratories and no changes in composition have been noticed at ETH in the 7 years they have been in use.

The "unknown" InterCarb reference materials were chosen to cover a wide natural range in $\delta^{47}$ and $\Delta_{47}$ values. These samples had to be available in large quantities, inexpensive, and if possible distributed by an organization with a long-term perspective in order to ensure future data quality and availability for the increasing number of laboratories globally.

\section{Materials and Methods}

\subsection{Sample Description}

The anchor samples ETH-1 (Carrara marble heated at $600{ }^{\circ} \mathrm{C}$ ), ETH-2 (synthetic carbonate heated at $600{ }^{\circ} \mathrm{C}$ ) and ETH-3 (Upper cretaceous chalk) are described in detail in Bernasconi et al. (2018).

IAEA-C1 (marble from Carrara, Italy) is distributed by the International Atomic Energy Agency (IAEA) as a mechanically crushed and milled product with grains ranging from 1.6 to $5 \mathrm{~mm}$. All $50 \mathrm{~g}$ provided were ground and thoroughly homogenized in a ball mill at ETH Zürich to a grain size of less than $100 \mu \mathrm{m}$ and transferred in $0.5 \mathrm{~g}$ aliquots to plastic vials for distribution. Nishida and Ishimura (2017) found that IAEA 603, which was produced from the same coarse marble as IAEA C-1, was isotopically inhomogeneous. Whitish grains (1-2 per 100 grains; grain weight, 8-63 $\mu \mathrm{g}$ ) were significantly depleted in ${ }^{18} \mathrm{O}$ and ${ }^{13} \mathrm{C}$ compared to translucent grains. In this study we found no evidence of inhomogeneity in $\Delta_{47}$ for sample aliquots of $80-110 \mu \mathrm{g}$ after the original material was ground in the ball mill.

IAEA-C2 is a freshwater travertine from Bavaria distributed by IAEA as a powder which was treated identically to IAEA-C1. XRD analysis shows it to be calcite (Figure S1).

ETH-4 is a commercially available synthetic calcium carbonate (Riedel-De Haën; calcium carbonate Puriss. p.a.; Lot No. 30800) determined to be calcite by XRD (Figure S2 with intermediate formation temperature and the same bulk isotope composition as ETH-2 (see Bernasconi et al., 2018 for details).

MERCK (Catalog No. 1.02059.0050; lot no. B1164559 515) is an ultra-pure, commercially available synthetic calcium carbonate determined to be calcite by XRD (Müller et al., 2019) and was chosen for its very low $\delta^{13} \mathrm{C}$ and $\delta^{18} \mathrm{O}$ values of approximately $-42.2 \%$ and $-15.5 \%$ (VPDB), respectively. This sample represents an extreme case of extrapolation from the $\delta_{47}-\Delta_{47}$ space defined by the anchor materials (Figure 2). The same product was recently used to prepare the carbon isotope reference material USGS44 by Qi et al. (2021) which, after careful determination of its $\Delta_{47}$ could be used as a substitute for the aliquots of MERCK distributed for this study. 


\subsection{Instrumentation}

The reported data were produced with a variety of preparation systems including custom built (13 laboratories) and commercial systems (11 laboratories; Protium MS IBEX, ThermoFisher Scientific Kiel IV device and $\mathrm{Nu}$ Instruments Nucarb). Reaction temperatures were generally $90^{\circ} \mathrm{C}$ for "large-sample" custom preparation systems and $70^{\circ} \mathrm{C}$ for the Kiel and the NuCarb. Four mass spectrometer types were used: Thermo Fisher Scientific MAT253 and 253Plus, Nu Instruments Perspective, and Elementar Isoprime 100. All participants contributed results they considered to be of "publication-grade" quality, based on their existing quality-control procedures.

\subsection{Clumped Isotope Compositions of the ETH Anchor Materials}

The clumped isotope compositions of the four ETH reference materials relative to the $\mathrm{CO}_{2}$ reference frame CDES were first reassessed based on new data provided by 10 laboratories that also provided HG and EG data measured during the same sessions as the ETH reference materials. The data were processed with the same Python script used for the carbonate data in order to avoid any differences in data processing (see Section 2.4).

Although, strictly speaking, ${ }^{13} \mathrm{C}-{ }^{18} \mathrm{O}$ clumping in carbonate represents a mass-63 anomaly, the clumped isotope composition of carbonate minerals is reported as $\Delta_{47}$, that is, as the mass- 47 excess in the $\mathrm{CO}_{2}$ produced by acid digestion of these minerals, including the respective temperature-dependent isotopic fractionation. As initially all reactions were carried out at $25{ }^{\circ} \mathrm{C}$ (Ghosh, Adkins, et al., 2006), the $\Delta_{47}$ values have traditionally been reported for a $25^{\circ} \mathrm{C}$ acid temperature. With the advent of automated extraction lines, reaction temperatures have been increased to $70{ }^{\circ} \mathrm{C}$ or $90{ }^{\circ} \mathrm{C}$. To account for the temperature dependence of the acid fractionation factor (Guo et al., 2009; Petersen et al., 2019) and to project these results back to the original $25{ }^{\circ} \mathrm{C}$ acid reactions, various acid temperature correction values have been reported over time, based on experimental observations and/or theoretical predictions. Given that here seven out of 10 laboratories reacted carbonates at $90^{\circ} \mathrm{C}$, two at $70{ }^{\circ} \mathrm{C}$, and only one at $25^{\circ} \mathrm{C}$, our redetermination of the $\Delta_{47}$ values of ETH-1/2/3/4 relative to the CDES projected to $25{ }^{\circ} \mathrm{C}$ would rely substantially on the accuracy of these acid temperature corrections (which typically range between 60 and $90 \mathrm{ppm}$ ). For this reason, we report the $\Delta_{47}$ values of $\mathrm{CO}_{2}$ produced by reacting ETH-1/2/3/4 at $90{ }^{\circ} \mathrm{C}$. With this choice the numerical effect of poorly known acid corrections is minimized because the data from $70{ }^{\circ} \mathrm{C}$ and $25{ }^{\circ} \mathrm{C}$ reactions have relatively little influence on the final, error-weighted average $\Delta_{47}$ values (cf. statistical weights in Figure 2). We thus propose to break with tradition and define the nominal $\Delta_{47}$ values of the anchor standards as those of $\mathrm{CO}_{2}$ produced at $90^{\circ} \mathrm{C}$, providing the most robust relationship to the CDES.

\subsection{Data Processing, Correction, and Error Assessment}

It should be stressed that the InterCarb experiment, by design, is not intended to grade the analytical performance of individual laboratories. Each participating laboratory (or mass spectrometer, in the case of laboratories with several instruments) was thus randomly assigned an anonymous identifying number. Within each laboratory, analyses were grouped in different analytical sessions defined by the participants themselves. An analytical session is generally defined by a time in which the behavior of the analytical system (preparation system, source tuning, backgrounds, isotope scrambling in the source) is considered to be similar. The database record of each analysis consists of a laboratory identifier, a session identifier, an analysis identifier, the name of the analyzed sample, the mass spectrometer model, the acid reaction temperature, the mass of the reacted carbonate, and background-corrected $\delta^{45}, \delta^{46}$, and $\delta^{47}$ values.

The only instrumental corrections to the raw data applied independently by each participating laboratory were background corrections ("Pressure Baseline Correction" or PBL) to the ion currents/voltages (Bernasconi et al., 2013; Fiebig et al., 2016, 2019; He et al., 2012). The PBL is strongly dependent on instrument design (it is not observed in some instruments) and configuration, and varies temporally depending on many factors. This correction, therefore, can only be carried out by each participating laboratory according to its own established procedures and monitoring. 
To avoid artifacts arising from different calculation/standardization procedures, rounding errors, and ${ }^{17} \mathrm{O}$ correction parameters, raw data from all laboratories were processed by a single Python script (http://doi. org/10.5281/zenodo.4314448) based on data reduction, standardization and error propagation methods described in detail in the companion paper (Daëron, 2021). Here we briefly summarize these calculations.

Session-averaged, background-corrected $\delta^{45}$ and $\delta^{46}$ values for each of the three anchor samples were first used to calculate the bulk isotope composition of the working gas used in each session, based on (a) previously reported $\delta^{13} \mathrm{C}_{\mathrm{VPDB}}$ and $\delta^{18} \mathrm{O}_{\mathrm{VPDB}}$ values of ETH-1, ETH-2, and ETH-3 (Bernasconi et al., 2018), (b) the IUPAC ${ }^{17} \mathrm{O}$ correction parameters of Brand et al. (2010), and (c) a temperature-dependent oxygen-18 acid fractionation factor between $\mathrm{CO}_{2}$ and calcite of Kim et al. (2015). This recalculation of working gas bulk compositions avoids (small) discrepancies potentially introduced by inaccuracies in the nominal compositions of the working gases.

Raw $\Delta_{47}$ values were computed according to:

$$
\Delta_{47}^{\text {raw }}=R^{47} / R^{47 *}-1
$$

where $R^{47}$ is the measured ratio and $R^{47 *}$ the calculated stochastic ratio of mass 47 over mass 44 of $\mathrm{CO}_{2}$, assuming perfectly linear IRMS measurements and a stochastic working gas. Values are then normalized to "absolute" $\Delta_{47}$ values (noted $\Delta_{47}^{\text {abs }}$ in the equation below, and simply $\Delta_{47}$ thereafter) using session-specific relationships of the form:

$$
\Delta_{47}^{\mathrm{raw}}=a \Delta_{47}^{\mathrm{abs}}+b \delta^{47}+c
$$

For each session, the best-fit standardization parameters (a, $b, \mathrm{c})$ are computed from an unweighted least squares regression, treating $\Delta_{47}^{\text {raw }}$ as the response variable, only considering the three anchor samples ETH1, ETH-2, and ETH-3. Note the advantage of this form over that in Dennis et al. (2011) is the ability to have three standards with distinct $\Delta_{47}$ values whilst being able to solve for $b$ (compositional nonlinearity) (Daëron et al., 2016). Absolute $\Delta_{47}$ values are then computed for all replicates within that session. Standardization parameters for all sessions are listed in Table 2.

Throughout this study, the analytical error assigned to each individual raw $\Delta_{47}$ analysis is equal to the pooled "external" repeatability of raw $\Delta_{47}$ measurements of anchors and unknowns within each session. In the figures and tables, final measurement uncertainties are reported as standard errors and/or $95 \%$ confidence limits, considering fully propagated errors taking into account reference frame corrections. In Figures 2 and 4, different types of error bars are used to represent analytical errors only considering uncertainties in the analyses of a given sample or the full uncertainty considering standardization uncertainties (the "autogenic" errors of Daëron, 2021). In both cases, the analytical error assigned to each individual raw $\Delta_{47}$ analysis is equal to the pooled "external" repeatability of raw $\Delta_{47}$ measurements for all samples (anchors and unknowns) within each session. This treatment of error is a new approach that more fully accounts for error in both the sample measurement and reference frame.

\section{Results and Discussion}

\subsection{Redetermination of Nominal $\Delta_{47}$ Values for the ETH Standards Relative to Heated and Equilibrated $\mathrm{CO}_{2}$ Gases}

The weighted averages of the four standards (projected to $90{ }^{\circ} \mathrm{C}$ for the reactions at 25 and $70{ }^{\circ} \mathrm{C}$ using the acid temperature correction suggested by Petersen et al., 2019), comprising 873 analyses of the carbonate standards and 946 heated and equilibrated gases from 10 different laboratories, are reported in Table 1 and Figure 2. The large number of analyses and the appropriate consideration of the errors on the anchors $\left(\mathrm{CO}_{2}\right.$ gas analyses) distinguishes this effort from previous work and allow a robust redetermination of the accepted values of the ETH reference materials with 1SE uncertainties of 2 ppm or less.

When compared with Bernasconi et al. (2018), the average $\Delta_{47}$ values ETH-1 and ETH-2, projected back to $25{ }^{\circ} \mathrm{C}(+0.088 \%$ ) , are respectively 0.035 and $0.040 \%$ o more positive than the original values, whereas ETH-3 
Table 1

Newly Determined Nominal $\triangle_{47}$ Values of the ETH Standards Projected to $90{ }^{\circ} \mathrm{C}$ Acid Reaction Using Acid Correction Factors of - $0.088 \%$ and -0.022\% for $25{ }^{\circ} \mathrm{C}$ and $70{ }^{\circ} \mathrm{C}$ Reactions, Respectively (Petersen et al., 2019)

\begin{tabular}{|c|c|c|c|c|c|c|c|c|c|c|c|c|}
\hline \multicolumn{2}{|c|}{ Laboratory } & All & $A$ & $B$ & $C$ & $D$ & E & $F$ & $G$ & $H$ & $I$ & $J$ \\
\hline \multicolumn{2}{|c|}{$N$ of sessions } & 34 & 4 & 4 & 11 & 7 & 1 & 2 & 1 & 1 & 1 & 2 \\
\hline \multicolumn{2}{|c|}{$N$ of $\mathrm{H} / \mathrm{E} \mathrm{CO}_{2}$} & 946 & 44 & 193 & 257 & 85 & 47 & 21 & 38 & 192 & 13 & 56 \\
\hline \multirow[t]{4}{*}{ ETH-1 } & $N$ of analyses & 232 & 34 & 14 & 5 & 54 & 4 & 4 & 19 & 58 & 8 & 32 \\
\hline & $\Delta_{47}\left(\% \circ ; 90^{\circ} \mathrm{C}\right.$ acid $)$ & 0.2052 & 0.2016 & 0.1926 & 0.2108 & 0.1940 & 0.1601 & 0.2013 & 0.2143 & 0.1932 & 0.2183 & 0.2152 \\
\hline & $\pm 1 \mathrm{SE}$ & 0.0016 & 0.0046 & 0.0058 & 0.0069 & 0.0042 & 0.0245 & 0.0107 & 0.0032 & 0.0045 & 0.0109 & 0.0036 \\
\hline & Statistical weight & & 0.118 & 0.074 & 0.053 & 0.146 & 0.004 & 0.022 & 0.241 & 0.124 & 0.021 & 0.197 \\
\hline \multirow[t]{4}{*}{ ETH-2 } & $N$ of analyses & 215 & 23 & 13 & 11 & 51 & 4 & 4 & 18 & 51 & 8 & 32 \\
\hline & $\Delta_{47}\left(\% \circ ; 90^{\circ} \mathrm{C}\right.$ acid $)$ & 0.2085 & 0.2077 & 0.1840 & 0.2225 & 0.1978 & 0.1374 & 0.1650 & 0.2141 & 0.1968 & 0.2172 & 0.2170 \\
\hline & $\pm 1 \mathrm{SE}$ & 0.0015 & 0.0047 & 0.0070 & 0.0046 & 0.0050 & 0.0233 & 0.0101 & 0.0029 & 0.0043 & 0.0154 & 0.0033 \\
\hline & Statistical weight & & 0.105 & 0.047 & 0.108 & 0.092 & 0.004 & 0.023 & 0.272 & 0.125 & 0.010 & 0.213 \\
\hline \multirow[t]{4}{*}{ ETH-3 } & $N$ of analyses & 264 & 55 & 15 & 20 & 54 & 4 & 5 & 15 & 59 & 8 & 29 \\
\hline & $\Delta_{47}\left(\% \circ ; 90^{\circ} \mathrm{C}\right.$ acid $)$ & 0.6132 & 0.6156 & 0.5975 & 0.6169 & 0.6102 & 0.5950 & 0.6143 & 0.6159 & 0.6094 & 0.6428 & 0.6124 \\
\hline & $\pm 1 \mathrm{SE}$ & 0.0014 & 0.0037 & 0.0056 & 0.0033 & 0.0038 & 0.0237 & 0.0099 & 0.0033 & 0.0042 & 0.0103 & 0.0035 \\
\hline & Statistical weight & & 0.140 & 0.062 & 0.175 & 0.134 & 0.003 & 0.020 & 0.179 & 0.110 & 0.018 & 0.158 \\
\hline \multirow[t]{4}{*}{ ETH-4 } & $N$ of analyses & 162 & 10 & 12 & 5 & 55 & 4 & 4 & 12 & 47 & 7 & 6 \\
\hline & $\Delta_{47}\left(\% \circ ; 90^{\circ} \mathrm{C}\right.$ acid $)$ & 0.4505 & 0.4438 & 0.4230 & 0.4624 & 0.4506 & 0.4230 & 0.4454 & 0.4560 & 0.4414 & 0.4831 & 0.4646 \\
\hline & $\pm 1 \mathrm{SE}$ & 0.0018 & 0.0058 & 0.0071 & 0.0068 & 0.0049 & 0.0226 & 0.0095 & 0.0032 & 0.0042 & 0.0161 & 0.0057 \\
\hline & Statistical weight & - & 0.093 & 0.064 & 0.068 & 0.133 & 0.006 & 0.035 & 0.314 & 0.177 & 0.012 & 0.097 \\
\hline
\end{tabular}

Note. Reported standard errors represent analytical uncertainties associated both with reference frame errors (HG/EG) and carbonate sample reproducibility (Daëron, 2021).

increases by 0.010 and ETH-4 by $0.031 \%$. A similar positive offset of $\Delta_{47}$ compared to the values reported in Bernasconi et al. (2018) has also been reported in Fiebig et al. (2019), Bajnai et al. (2020), and Thaler et al. (2020).

The observation that these changes in nominal values decrease as $\Delta_{47}$ increases suggests a simple hypothesis to explain this discrepancy: in the original study of Meckler et al. (2014), the carbonate samples and the heated/equilibrated $\mathrm{CO}_{2}$ gases experienced different analytical procedures. The HGs were measured as large samples at constant beam intensity through a different capillary than the carbonates, which were measured using the microvolume and a decreasing beam. The potential effects of partial re-equilibration for the heated gases in the gas preparation line or in the capillaries of the mass spectrometer could be significant whereas it would be minuscule for the gases equilibrated at $25^{\circ}$, leading to an overestimation of $\Delta_{47}$ scale compression and thus of the stretching applied to the $\Delta_{47}$ scale toward theoretical values. The observed changes in apparent ETH-1 and ETH- $2 \Delta_{47}$ values may therefore simply reflect partial re-equilibration of heated gases at the time of measurements at ETH (and reported in Meckler et al., 2014), increasing their values in the original study by about $0.05 \%$ (Figure 3 ).

It has been suggested previously that ETH-1 and ETH-2 should be indistinguishable in $\Delta_{47}$ and close to stochastic distribution (Müller, Violay, et al., 2017). This is because $\Delta_{47}$ values of ETH-1 and ETH-2, originally heated to $600{ }^{\circ} \mathrm{C}$, were found to be higher by only around $0.006 \%$ o from the same carbonates heated at $1000{ }^{\circ} \mathrm{C}$ to achieve stochastic distribution of the isotopes. However, additional test measurements in multiple laboratories of samples heated at $>1000{ }^{\circ} \mathrm{C}$ are necessary to confirm this observation.

One laboratory (Laboratory F) did however observe a large difference in the value for ETH-1 and ETH-2, although their values of ETH-3 and ETH-4 are similar to other laboratories. The reason for these inconsistencies is probably due to the fact that ETH-1 was only measured four times with a limited number of HG/EG, and ETH-2 and ETH-4 were not measured in the same session. In addition, the laboratories with 


\section{ETH-4}

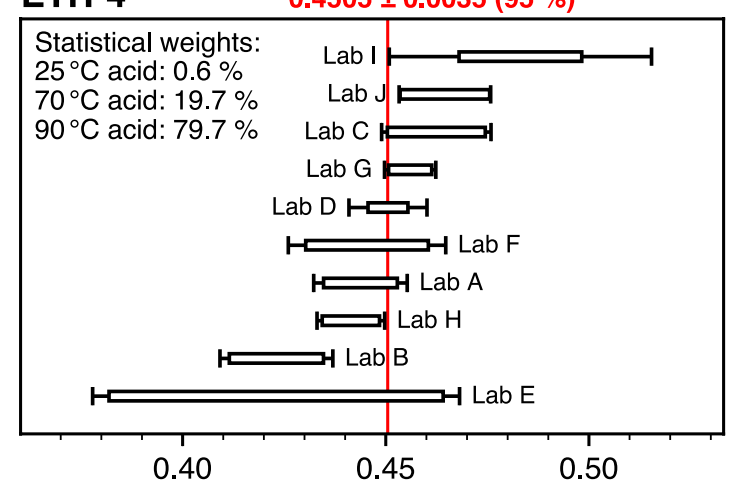

\section{ETH-2}

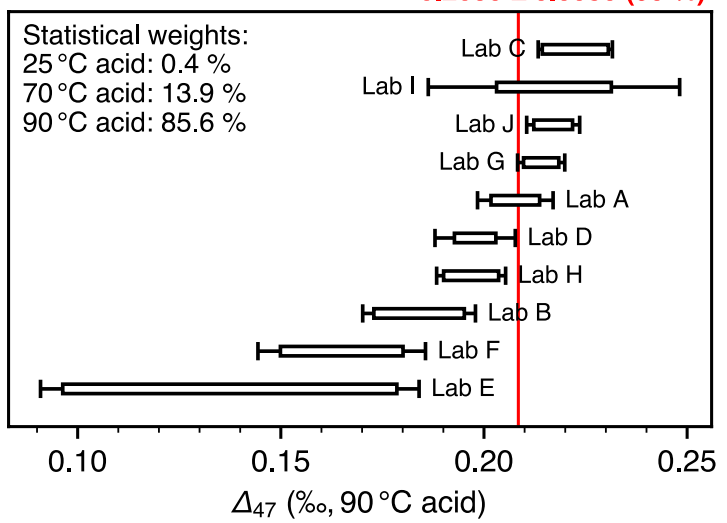

\section{ETH-3}

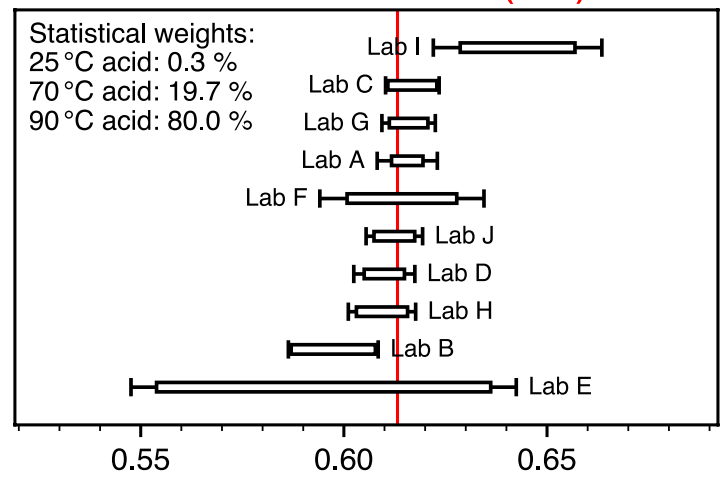

ETH-1

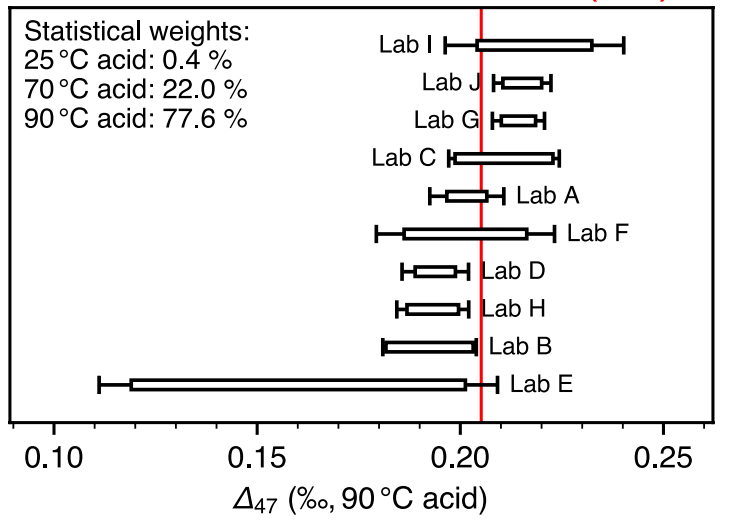

Figure 2. New determination of $\Delta_{47}$ values for the four ETH standards relative to the CDES using updated $\mathrm{CO}_{2}$ equilibrium values. These measurements, using acid reaction temperatures of $90{ }^{\circ} \mathrm{C}, 70{ }^{\circ} \mathrm{C}$, or $25^{\circ} \mathrm{C}$, are projected to $90{ }^{\circ} \mathrm{C}$ using acid corrections of $-0.088 \%$ and $-0.022 \%$ or $25{ }^{\circ} \mathrm{C}$ and $70{ }^{\circ} \mathrm{C}$ reactions, respectively (Petersen et al., 2019). Error bars correspond to $95 \%$ confidence limits taking into account fully propagated errors (i.e., taking into account errors in both unknown and anchor analyses). Boxes correspond to $95 \%$ confidence limits not accounting for normalization errors (i.e., only taking into account errors in unknown analyses). Red numbers are the error-weighted average values (with statistical weights summarized in upper-left corners). All plots have the same horizontal scales for the different samples. CDES, Carbon Dioxide Equilibrium Scale.

the smallest number of replicate measurements have uncertainties that are systematically larger (Table 1). These results highlight the importance of strict correction procedures in clumped isotope analysis. Sufficient replication of both standards and samples is critical and, if insufficient, offsets can arise when comparing results from different sessions. Due to these difficulties it is good practice to spread replicates of the same sample in different sessions over longer periods of time to obtain accurate results and follow a $\sim 50: 50$ standard to sample replicate ratio.

Based on the results above, the difference between the average of ETH1/2 and ETH-3 is reduced by $0.028 \%$, thus leading to a compression of the scale by about $5.8 \%$ compared to the values reported by Bernasconi et al. (2018). As a consequence, the slopes of published temperature calibrations produced with carbonate standardization (Bernasconi et al., 2018; Jautzy et al., 2020; Kele et al., 2015; Meinicke et al., 2020; Peral et al., 2018; Piasecki et al., 2019) will become slightly shallower, with more positive $y$-intercepts. If $\Delta_{47}$ results from previous publications are also recalculated with the new standard values (see Section 3.4), however, changes in calculated formation temperatures will be negligible. For this reason, when comparing data from publications using old accepted values of the ETH standards for standardization (either those published by Meckler et al., 2014 or those recalculated with the IUPAC parameters by Bernasconi et al., 2018) to newer data, it is recommended to directly compare the reconstructed temperatures rather than recalculating $\Delta_{47}$. Full recalculation of old measurements usually requires the availability of the entire data set including standards and the same correction procedures (e.g., averaging methods) used in the original publications (but see Appendix A for an alternative calculation method). 


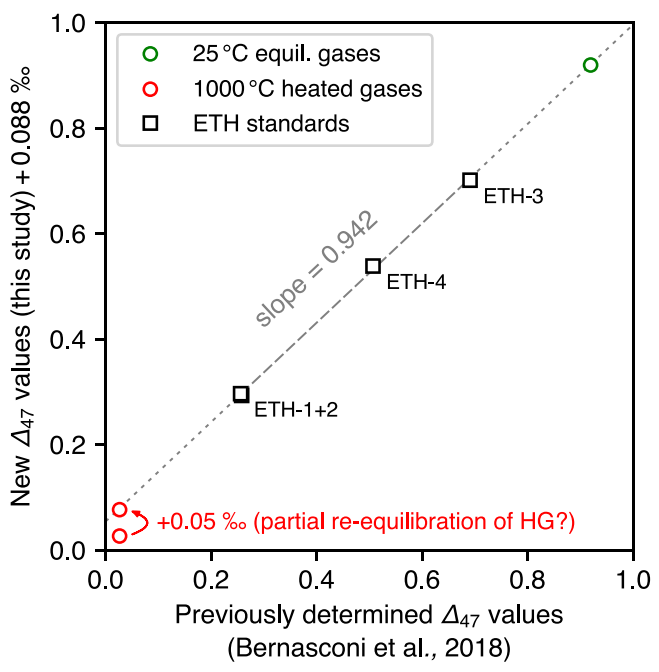

Figure 3. New nominal $\Delta_{47}$ values for the ETH standards compared to previously reported ones. The dashed gray line is a linear regression through the new versus old values of ETH-1/2/3/4, whose extrapolation coincides with $25^{\circ} \mathrm{C}$ equilibrated $\mathrm{CO}_{2}$ but not with heated gases. Apparent changes in the ETH-1/2/3/4 values thus scale linearly with the $\Delta_{47}$ difference between carbonate samples and $25^{\circ} \mathrm{C}$ equilibrated $\mathrm{CO}_{2}$, suggesting that $\Delta_{47}$ values of heated gases in the original study may have been biased by $\sim+0.05 \%$ o through partial re-equilibration at room temperature between the quenching of heated $\mathrm{CO}_{2}$ and its ionization in the isotope-ratio mass spectrometer source.

\subsection{InterCarb Results}

Results for the unknown carbonate samples were obtained from 25 mass spectrometers in 22 laboratories. The $\Delta_{47}$ values of the four unknown samples were normalized to the new community-derived values of ETH1, ETH-2, and ETH-3 of Table 1, then averaged per individual analytical session and mass spectrometer (Tables 2 and 3). Mean $\Delta_{47}$ values obtained for each sample in each mass spectrometer are shown in Figure 4. The details of each analytical session, including the number of samples and standards measured, the isotopic composition of the working standard, the scaling parameters and the internal reproducibilities (as 1SD) of the individual sessions are listed in Table 2. Some laboratories reported data for only a subset of the unknown samples, and both replication level and analytical reproducibility vary greatly from laboratory to laboratory (Table 2).

To clearly distinguish $\Delta_{47}$ values normalized to the CDES using carbonates rather than heated and equilibrated gases, we propose the new acronym (I-CDES), short for InterCarb-CDES, to reflect the use of the proposed InterCarb reference materials for data standardization (see Section 3.5 for more details).

The laboratory averages for the four unknowns show standard deviations of $0.011 \%$ or ETH-4 and IAEA-C1, $0.018 \%$ or IAEA-C2 and $0.024 \%$ or MERCK, the most extreme case of extrapolation (Table 3). Qualitatively, laboratories with stronger analytical constraints (i.e., better intralaboratory repeatability of $\Delta_{47}$ measurements and/or greater number of analyses) generally converge toward the overall mean value for each sample (Figure 4). This suggests that the observed interlaboratory variability is largely due to random errors that can be alleviated by replication, even for laboratories with relatively large analytical errors on individual measurements. It is also notable that fully propagated analytical errors that take into account uncertainties in the standardization procedure can be substantially larger than the errors based on the uncertainty associated with sample analyses alone, which is what is generally reported in the literature. The increase in error is also related to intralaboratory repeatability and the number of standards measured. In addition, the error increases for unknown samples whose compositions lie outside the "anchor triangle" defined by ETH-1/2/3. This is illustrated by the increased scatter and errors associated with MERCK, the carbonate farthest from the "anchor triangle," consistent with the models of Daëron (2021) (see also Kocken et al., 2019).

As seen in Table 2, there are stark differences in the total number of replicate analyses and the typical $\Delta_{47}$ reproducibility achieved in different laboratories. As a result, final uncertainties in the average $\Delta_{47}$ values of unknown samples vary considerably (Figure 4). Interlaboratory variability is smaller among laboratories with small analytical uncertainties, and larger among laboratories with few replicate analyses and/or poor analytical repeatability. If we chose only laboratories that have provided data with average standard errors below $0.01 \%$ (Table 3), which is within the shot-noise limits of modern IRMS instruments, interlaboratory standard deviation (1SD) becomes $\leq 9 \mathrm{ppm}$ for ETH-4 $(N=22)$, IAEA-C1 $(N=15)$, and IAEA-C2 $(N=13)$ and $\leq 0.015 \%$ for MERCK $(N=11$; with SE < 0.0135). We note that this does not significantly change the average value of the unknowns, and highlights the importance of sufficient sample replication to obtain accurate results.

Next we may assess whether interlaboratory discrepancies are significantly larger than expected from intralaboratory analytical uncertainties, that is, whether we can detect the effects of hypothetical unrecognized sources of scatter beyond known analytical errors.

In order to do so, we compute the "number-of-sigma" deviation obtained by each laboratory for each unknown sample, relative to that sample's overall weighted average value. For example, the sigma-deviation for sample ETH-4 and Lab01 is equal to (0.4477-0.4511)/0.0052 $=-0.66$ and that for MERCK and Lab13 is 
Table 2

Summary of All InterCarb Analyses

\begin{tabular}{|c|c|c|c|c|c|c|c|c|c|c|c|c|c|c|c|c|c|}
\hline \multicolumn{9}{|c|}{ Number of analyses } & \multicolumn{3}{|c|}{ Working gas } & \multicolumn{3}{|c|}{ Standardization parameters } & \multicolumn{3}{|c|}{ Reproducibility (ppm) } \\
\hline $\mathrm{Lab}$ & Session & $\mathrm{El}$ & E2 & E3 & $\mathrm{E} 4$ & $\mathrm{Cl}$ & $\mathrm{CZ}$ & M & $\mathrm{Nf}$ & $\delta^{13} \mathrm{C}_{\mathrm{VPDB}}$ & $\delta^{18} \mathrm{O}_{\text {vSMOW }}$ & $a$ & $b$ & $c$ & $\delta^{13} \mathrm{C}_{\mathrm{VPDB}}$ & $\delta^{18} \mathrm{O}_{\text {vSMOW }}$ & $\Delta_{47}$ \\
\hline \multirow[t]{3}{*}{01} & 01 & 16 & 17 & 10 & 7 & 0 & 0 & 0 & 46 & -3.58 & 25.38 & 0.91 & $\left(6.0 \times 10^{-4}\right)$ & -0.893 & 41 & 91 & 31.5 \\
\hline & 02 & 6 & 5 & 3 & 1 & 0 & 0 & 0 & 11 & -3.52 & 25.58 & 0.89 & $-2.1 \times 10^{-3}$ & -0.765 & 34 & 64 & 22.8 \\
\hline & 03 & 150 & 146 & 65 & 72 & 19 & 21 & 22 & 488 & -3.63 & 25.22 & 0.98 & $\left(-2.9 \times 10^{-5}\right)$ & -0.965 & 33 & 74 & 33.5 \\
\hline \multirow[t]{2}{*}{02} & 01 & 19 & 24 & 20 & 18 & 4 & 5 & 4 & 87 & -36.89 & 8.76 & 0.99 & $-5.6 \times 10^{-4}$ & -0.955 & 17 & 92 & 13.0 \\
\hline & 02 & 6 & 8 & 5 & 4 & 2 & 3 & 2 & 23 & -360.88 & 8.83 & 0.98 & $\left(-5.5 \times 10^{-4}\right)$ & -0.931 & 25 & 77 & 16.1 \\
\hline \multirow[t]{2}{*}{03} & 01 & 37 & 24 & 17 & 9 & 0 & 0 & 0 & 83 & -10.44 & 31.64 & 0.98 & $\left(-1.6 \times 10^{-4}\right)$ & -0.917 & 22 & 56 & 27.9 \\
\hline & 02 & 29 & 32 & 12 & 14 & 17 & 13 & 11 & 121 & -3.65 & 25.28 & 1.00 & $\left(-1.7 \times 10^{-4}\right)$ & -0.917 & 46 & 93 & 25.2 \\
\hline 04 & 01 & 6 & 9 & & 9 & 6 & 4 & - & 35 & -6.57 & 27.18 & 0.97 & $5.0 \times 10^{-3}$ & -1.022 & 259 & 562 & 40.6 \\
\hline \multirow[t]{3}{*}{05} & 01 & 3 & 3 & 5 & 2 & 3 & 2 & 2 & 13 & -100.43 & 31.31 & 0.95 & $1.7 \times 10^{-3}$ & -0.970 & 15 & 27 & 8.6 \\
\hline & 02 & 13 & 13 & 13 & 12 & 10 & 11 & 8 & 73 & -3.62 & 25.05 & 0.99 & $\left(3.8 \times 10^{-4}\right)$ & -0.968 & 15 & 24 & 20.9 \\
\hline & 03 & 7 & 10 & 10 & 8 & 5 & 4 & 4 & 41 & -3.63 & 25.06 & 0.90 & $1.1 \times 10^{-3}$ & -0.901 & 42 & 113 & 17.3 \\
\hline \multirow[t]{4}{*}{06} & 01 & 6 & 3 & 5 & 3 & 3 & 3 & 3 & 19 & -2.95 & 25.52 & 0.83 & $\left(-3.8 \times 10^{-4}\right)$ & -0.920 & 22 & 25 & 21.0 \\
\hline & 02 & 6 & 6 & 6 & 6 & 0 & 0 & 0 & 20 & -2.98 & 24.93 & 0.92 & $\left(-9.9 \times 10^{-5}\right)$ & -0.920 & 14 & 71 & 13.3 \\
\hline & 03 & 3 & 3 & 3 & 3 & 3 & 3 & 3 & 14 & -3.01 & 24.90 & 0.88 & $\left(3.6 \times 10^{-4}\right)$ & -0.932 & 10 & 43 & 9.4 \\
\hline & 04 & 6 & 6 & 6 & 0 & 6 & 6 & 6 & 30 & -2.95 & 25.28 & 0.90 & $\left(-1.4 \times 10^{-4}\right)$ & -0.926 & 18 & 61 & 17.3 \\
\hline 07 & 01 & - & 4 & 4 & - & 4 & 4 & - & 19 & -11.64 & 35.75 & 0.87 & $\left.3.5 \times 10^{-3}\right)$ & -0.836 & 91 & 303 & 23.9 \\
\hline \multirow[t]{16}{*}{08} & 01 & 5 & 6 & 9 & 4 & 4 & 4 & 4 & 29 & -2.68 & 25.86 & 0.94 & $\left(-9.2 \times 10^{-4}\right)$ & -0.686 & 13 & 25 & 28.4 \\
\hline & 02 & 5 & 4 & 14 & 6 & 4 & 5 & 4 & 35 & -2.64 & 25.96 & 0.94 & $\left(8.6 \times 10^{-4}\right)$ & -0.741 & 83 & 88 & 33.2 \\
\hline & 03 & 4 & 4 & 13 & 4 & 3 & 5 & 6 & 32 & -2.64 & 25.91 & 0.93 & $\left(-1.7 \times 10^{-4}\right)$ & -0.728 & 15 & 33 & 33.2 \\
\hline & 04 & 4 & 5 & 9 & 5 & 4 & 4 & 4 & 28 & -2.67 & 25.85 & 0.85 & $\left(1.3 \times 10^{-4}\right)$ & -0.629 & 17 & 51 & 44.5 \\
\hline & OS & 3 & 6 & 8 & 4 & 4 & 4 & 4 & 26 & -20.70 & 25.79 & 0.87 & $\left(1.3 \times 10^{-3}\right)$ & -0.660 & 16 & 56 & 43.3 \\
\hline & 06 & 4 & 4 & 16 & 6 & 6 & 6 & 4 & 39 & -2.63 & 25.90 & 0.92 & $\left(3.9 \times 10^{-4}\right)$ & -0.693 & 85 & 54 & 37.8 \\
\hline & 07 & 3 & 4 & 16 & 6 & 6 & 4 & 6 & 38 & -2.66 & 25.90 & 0.96 & $\left(-1.9 \times 10^{-3}\right)$ & -0.709 & 19 & 52 & 48.8 \\
\hline & 08 & 4 & 4 & 16 & 4 & 4 & 4 & 4 & 33 & -2.66 & 25.89 & 1.03 & $\left(3.9 \times 10^{-5}\right)$ & -0.806 & 12 & 46 & 42.7 \\
\hline & 09 & 5 & 6 & 8 & 4 & 4 & 3 & 4 & 27 & -2.67 & 25.84 & 0.92 & $\left(1.6 \times 10^{-4}\right)$ & -0.722 & 19 & 25 & 46.7 \\
\hline & 10 & 6 & 6 & 6 & 4 & 4 & 2 & 4 & 25 & -2.63 & 25.91 & 0.97 & $\left(4.4 \times 10^{-4}\right)$ & -0.767 & 36 & 39 & 40.5 \\
\hline & 11 & 6 & 5 & 8 & 4 & 4 & 3 & 4 & 27 & -2.67 & 25.87 & 0.97 & $\left(2.5 \times 10^{-4}\right)$ & -0.760 & 11 & 31 & 49.5 \\
\hline & 12 & 6 & 6 & 8 & 3 & 4 & 4 & 4 & 28 & -2.66 & 25.86 & 1.02 & $\left(7.9 \times 10^{-4}\right)$ & -0.767 & 58 & 40 & 61.3 \\
\hline & 13 & 4 & 6 & 8 & 6 & 4 & 4 & 6 & 31 & -2.63 & 25.93 & 0.89 & $\left(1.3 \times 10^{-3}\right)$ & -0.685 & 19 & 38 & 41.0 \\
\hline & 14 & 5 & 7 & 5 & 4 & 4 & 4 & 4 & 26 & -2.59 & 25.90 & 0.90 & $\left(-3.6 \times 10^{-4}\right)$ & -0.665 & 76 & 104 & 27.4 \\
\hline & 15 & 6 & 4 & 8 & 4 & 4 & 4 & 4 & 27 & -2.68 & 25.79 & 0.95 & $-2.0 \times 10^{-3}$ & -0.685 & 21 & 52 & 36.0 \\
\hline & 16 & 2 & 2 & 10 & 5 & 4 & 2 & 4 & 22 & -2.63 & 25.89 & 0.96 & $\left(-5.4 \times 10^{-4}\right)$ & -0.765 & 40 & 39 & 38.8 \\
\hline \multirow[t]{4}{*}{09} & 01 & 4 & 4 & 5 & 6 & 0 & 0 & 0 & 15 & -3.60 & 25.36 & 0.89 & $3.8 \times 10^{-3}$ & -0.856 & 22 & 74 & 28.3 \\
\hline & 02 & 26 & 19 & 16 & 24 & 0 & 0 & 0 & 81 & -3.36 & 19.94 & 0.90 & $5.2 \times 10^{-3}$ & -0.928 & 46 & 98 & 18.4 \\
\hline & 03 & 21 & 17 & 13 & 19 & 0 & 1 & 0 & 66 & -3.53 & 24.49 & 0.92 & $-1.0 \times 10^{-2}$ & -0.968 & 72 & 1667 & 22.4 \\
\hline & 04 & 19 & 16 & 13 & 16 & 8 & 7 & 2 & 74 & -3.60 & 25.27 & 0.98 & $-9.6 \times 10^{-3}$ & -0.994 & 44 & 56 & 16.0 \\
\hline \multirow[t]{3}{*}{10} & 01 & 7 & 7 & 8 & 2 & 0 & 11 & 0 & 30 & -7.43 & 32.38 & 0.98 & $1.9 \times 10^{-3}$ & -1.077 & 24 & 38 & 35.1 \\
\hline & 02 & 15 & 15 & 21 & 15 & 11 & 20 & 11 & 101 & -7.41 & 32.42 & 0.93 & $\left(-2.0 \times 10^{-4}\right)$ & -0.877 & 25 & 44 & 23.0 \\
\hline & 03 & 17 & 18 & 25 & 9 & 22 & 31 & 20 & 135 & -7.43 & 32.37 & 0.96 & $\left(-2.8 \times 10^{-4}\right)$ & -0.900 & 31 & 92 & 30.0 \\
\hline
\end{tabular}


Table 2

Continued

\begin{tabular}{|c|c|c|c|c|c|c|c|c|c|c|c|c|c|c|c|c|c|}
\hline \multicolumn{9}{|c|}{ Number of analyses } & \multicolumn{3}{|c|}{ Working gas } & \multicolumn{3}{|c|}{ Standardization parameters } & \multicolumn{3}{|c|}{ Reproducibility (ppm) } \\
\hline Lab & Session & El & $\mathrm{E} 2$ & E3 & E4 & $\mathrm{Cl}$ & $\mathrm{CZ}$ & M & $\mathrm{Nf}$ & $\delta^{13} \mathrm{C}_{\mathrm{VPDB}}$ & $\delta^{18} \mathrm{O}_{\text {vSMOW }}$ & $a$ & $b$ & $c$ & $\delta^{13} \mathrm{C}_{\mathrm{VPDB}}$ & $\delta^{18} \mathrm{O}_{\text {vSMOW }}$ & $\Delta_{47}$ \\
\hline \multirow[t]{5}{*}{11} & 01 & 24 & 24 & 28 & 28 & 0 & 0 & 0 & 100 & -3.63 & 25.37 & 0.99 & $\left(-8.1 \times 10^{-5}\right)$ & -0.974 & 23 & 91 & 19.1 \\
\hline & 02 & 20 & 18 & 15 & 15 & 0 & 0 & 0 & 64 & -3.60 & 25.53 & 0.98 & $\left(3.5 \times 10^{-4}\right)$ & -0.996 & 35 & 270 & 28.9 \\
\hline & 03 & 69 & 62 & 74 & 66 & 13 & 13 & 8 & 298 & -3.02 & 24.99 & 0.91 & $\left(-2.2 \times 10^{-4}\right)$ & -1.065 & 34 & 89 & 25.0 \\
\hline & 04 & 36 & 34 & 34 & 35 & 6 & 4 & 8 & 150 & -3.01 & 25.08 & 1.00 & $\left(-3.1 \times 10^{-4}\right)$ & -1.088 & 87 & 210 & 33.7 \\
\hline & OS & 90 & 83 & 92 & 78 & 12 & 10 & 9 & 367 & -2.76 & 25.78 & 0.98 & $\left(-5.0 \times 10^{-4}\right)$ & -1.088 & 97 & 317 & 19.3 \\
\hline \multirow[t]{4}{*}{12} & 01 & 7 & 7 & 9 & 5 & 5 & 6 & 5 & 37 & -3.75 & 25.15 & 0.89 & $3.7 \times 10^{-3}$ & -0.904 & 7 & 41 & 10.2 \\
\hline & 02 & 7 & 6 & 6 & 6 & 5 & 5 & 5 & 33 & -3.74 & 25.18 & 0.87 & $4.6 \times 10^{-3}$ & -0.897 & 8 & so & 9.3 \\
\hline & 03 & 8 & 7 & 12 & 5 & 5 & 5 & 5 & 40 & -3.74 & 25.17 & 0.88 & $5.5 \times 10^{-3}$ & -0.909 & 9 & 51 & 9.7 \\
\hline & 04 & 6 & 7 & 6 & 5 & 5 & 5 & 4 & 31 & -3.74 & 25.17 & 0.88 & $5.3 \times 10^{-3}$ & -0.908 & 7 & 51 & 8.7 \\
\hline 13 & 01 & 58 & 51 & 59 & 47 & 6 & 12 & 9 & 235 & -10.29 & 330.18 & 0.98 & $-3.7 \times 10^{-4}$ & -0.993 & 176 & 239 & 26.8 \\
\hline \multirow[t]{10}{*}{14} & 01 & 4 & 7 & 10 & 10 & 0 & 0 & 0 & 27 & -3.63 & 24.95 & 0.93 & $\left(1.3 \times 10^{-4}\right)$ & -0.972 & 42 & 159 & 19.3 \\
\hline & 02 & 10 & 11 & 8 & 7 & 0 & 0 & 0 & 32 & -3.61 & 25.04 & 0.97 & $\left(5.8 \times 10^{-4}\right)$ & -1.021 & 40 & 128 & 30.0 \\
\hline & 03 & 6 & 4 & 4 & 3 & 0 & 0 & 0 & 13 & -10.38 & 31.93 & 0.84 & $-1.7 \times 10^{-3}$ & -0.747 & 39 & 59 & 20.5 \\
\hline & 04 & 2 & 2 & 2 & 2 & 0 & 0 & 0 & 4 & -100.40 & 31.92 & 0.86 & $-1.0 \times 10^{-3}$ & -0.794 & 20 & 29 & 9.2 \\
\hline & 05 & 4 & 4 & 3 & 4 & 0 & 0 & 0 & 11 & -100.40 & 31.92 & 0.91 & $-1.6 \times 10^{-33}$ & -0.807 & 27 & 60 & 11.0 \\
\hline & 06 & 5 & 6 & 6 & 7 & 0 & 0 & 0 & 20 & -10.43 & 31.84 & 0.99 & $\left(1.3 \times 10^{-4}\right)$ & -0.908 & 39 & 53 & 22.4 \\
\hline & 07 & 3 & 5 & 2 & 1 & 0 & 0 & 0 & 7 & -100.41 & 31.85 & 0.97 & $\left(-1.7 \times 10^{-4}\right)$ & -0.877 & 51 & 43 & 12.8 \\
\hline & 08 & 11 & 7 & 3 & 5 & 0 & 0 & 0 & 22 & -10.47 & 31.66 & 0.94 & $-7.8 \times 10^{-4}$ & -0.920 & 61 & 84 & 23.4 \\
\hline & 09 & 4 & 2 & 3 & 4 & 0 & 0 & 0 & 9 & -100.43 & 31.82 & 0.95 & $\left(-4.8 \times 10^{-4}\right)$ & -0.907 & 55 & 83 & 12.0 \\
\hline & 10 & 4 & 4 & 1 & 3 & 0 & 0 & 0 & 8 & -10.49 & 31.73 & 0.99 & $\left(1.7 \times 10^{-4}\right)$ & -0.926 & 40 & 71 & 13.3 \\
\hline \multirow[t]{2}{*}{15} & 01 & 4 & 4 & 4 & 4 & 0 & 0 & 0 & 12 & -320.89 & 360.92 & 0.96 & $-2.5 \times 10^{-3}$ & -0.887 & 87 & 70 & 14.6 \\
\hline & 02 & 4 & 4 & 4 & 4 & 4 & 4 & 4 & 21 & -3.72 & 24.98 & 1.02 & $4.6 \times 10^{-3}$ & -1.027 & 59 & 41 & 14.0 \\
\hline 16 & 01 & - & 6 & 6 & 4 & 4 & - & - & 23 & -10.49 & 31.56 & 0.99 & $-4.1 \times 10^{-3}$ & -0.979 & 47 & 109 & 10.1 \\
\hline 17 & 01 & - & 5 & - & - & 6 & 6 & - & 23 & -9.73 & 23.81 & 0.81 & $\left(6.3 \times 10^{-4}\right)$ & -0.940 & 65 & 204 & 29.3 \\
\hline \multirow[t]{3}{*}{18} & 01 & 168 & 147 & 172 & 169 & 20 & 20 & 25 & 714 & -3.45 & 25.25 & 0.81 & $\left(1.5 \times 10^{-4}\right)$ & -0.722 & 65 & 110 & 370.7 \\
\hline & 02 & 17 & 14 & 17 & 13 & 4 & 4 & 4 & 66 & -30.41 & 250.42 & 0.83 & $\left(1.6 \times 10^{-5}\right)$ & -0.761 & 21 & 52 & 45.7 \\
\hline & 03 & 11 & 12 & 13 & 14 & 2 & 4 & 2 & 51 & -3.52 & 25.12 & 0.96 & $\left(6.0 \times 10^{-4}\right) 1$ & -0.835 & 23 & 45 & 40.5 \\
\hline \multirow[t]{2}{*}{19} & 01 & 4 & 4 & 5 & 7 & 5 & 4 & 4 & 26 & -24.48 & 25.66 & 0.99 & $\left(2.0 \times 10^{-4}\right)$ & -0.970 & 69 & 193 & 23.4 \\
\hline & 02 & 7 & 8 & 10 & 7 & 0 & 0 & 0 & 28 & 5.03 & 38.66 & 0.99 & $\left(2.0 \times 10^{-4}\right)$ & -0.962 & 164 & 416 & 22.5 \\
\hline 20 & 01 & 9 & 6 & 6 & 6 & 0 & 0 & 0 & 23 & -3.63 & 28.89 & 0.93 & $-2.1 \times 10^{-3}$ & -0.921 & 11 & so & 14.3 \\
\hline 21 & 01 & - & - & - & - & 0 & 0 & 0 & 8 & -3.62 & 25.20 & 0.90 & $1.0 \times 10^{-3}$ & -0.886 & 65 & 139 & 11.4 \\
\hline 22 & 01 & 8 & 8 & 8 & & 0 & 0 & - & 33 & -3.54 & 25.37 & 0.98 & $9.9 \times 10^{-3}$ & -0.951 & 155 & 443 & 20.5 \\
\hline 23 & 01 & 6 & 6 & 6 & 6 & 0 & 0 & - & 20 & -100.77 & 31.02 & 1.00 & $4.4 \times 10^{-3}$ & -0.948 & 47 & 91 & 20.5 \\
\hline 24 & 01 & 19 & 18 & 15 & 12 & 0 & 0 & 0 & 60 & -4.40 & 25.32 & 0.98 & $\left(2.1 \times 10^{-4}\right)$ & -0.955 & 42 & 107 & 9.9 \\
\hline \multirow[t]{2}{*}{26} & 01 & 4 & 4 & 4 & & 3 & - & - & 19 & -40.04 & 5.51 & 0.89 & $\left(2.2 \times 10^{-4}\right)$ & -0.998 & 96 & 145 & 15.0 \\
\hline & 02 & 6 & 7 & 6 & & 3 & - & - & 24 & -400.03 & 5.40 & 0.92 & $(-1.1 \times 10-4)$ & -1.014 & 50 & 88 & 8.7 \\
\hline
\end{tabular}

Notes. Nf is the number of degrees of freedom when estimating pooled analytical repeatabilities and standardization model uncertainties. Standardization parameters $a, b$, and $c$ refer to the scrambling factor in the source, the compositional slope due to positive or negative backgrounds in the collectors and the working gas offset, respectively (see Section 2.4 and Daëron, 2021). Values of standardization parameter $b$ which are statistically indistinguishable from zero at 95\% confidence level are reported in parenthesis. Reproducibility is reported as $1 \mathrm{SD}$. 
Table 3

Average $\Delta_{47}$ Values ( $\pm 1 S E$, Fully Propagated Uncertainties) Obtained by Each Mass Spectrometer From the 22 Laboratories

\begin{tabular}{|c|c|c|c|c|c|c|c|c|}
\hline \multirow[b]{2}{*}{ MS } & \multicolumn{2}{|l|}{ ETH-4 } & \multicolumn{2}{|l|}{ IAEA-C1 } & \multicolumn{2}{|l|}{ IAEA-C2 } & \multicolumn{2}{|l|}{ MERCK } \\
\hline & $\begin{array}{c}\Delta_{47(\mathrm{I}-\mathrm{CDES}} \\
(\% o \pm 1 \mathrm{SE})\end{array}$ & $N$ & $\begin{array}{c}\Delta_{47(\mathrm{I}-\mathrm{CDES}} \\
(\% \circ \pm 1 \mathrm{SE})\end{array}$ & $N$ & $\begin{array}{c}\Delta_{47(\mathrm{I}-\mathrm{CDES}} \\
(\% \circ \pm 1 \mathrm{SE})\end{array}$ & $N$ & $\begin{array}{c}\Delta_{47(\mathrm{I}-\mathrm{CDES}} \\
(\% \circ \pm 1 \mathrm{SE})\end{array}$ & $N$ \\
\hline 1 & $0.4477 \pm 0.0052$ & 80 & $0.2773 \pm 0.0080$ & 19 & $0.6275 \pm 0.0088$ & 21 & $0.4991 \pm 0.0105$ & 22 \\
\hline 2 & $0.4499 \pm 0.0044$ & 22 & $0.3086 \pm 0.0060$ & 6 & $0.6299 \pm 0.0061$ & 8 & $0.5025 \pm 0.0089$ & 6 \\
\hline 3 & $0.4430 \pm 0.0074$ & 23 & $0.3114 \pm 0.0073$ & 17 & $0.6427 \pm 0.0112$ & 13 & $0.5235 \pm 0.0152$ & 11 \\
\hline 4 & $0.4841 \pm 0.0248$ & 9 & $0.2959 \pm 0.0215$ & 6 & $0.6368 \pm 0.0291$ & 4 & - & - \\
\hline 5 & $0.4734 \pm 0.0055$ & 22 & $0.2916 \pm 0.0044$ & 18 & $0.6378 \pm 0.0057$ & 17 & $0.4987 \pm 0.0094$ & 14 \\
\hline 6 & $0.4545 \pm 0.0060$ & 12 & $0.3004 \pm 0.0051$ & 12 & $0.6471 \pm 0.0069$ & 12 & $0.5229 \pm 0.0116$ & 12 \\
\hline 7 & $0.4607 \pm 0.0066$ & 8 & $0.3099 \pm 0.0042$ & 16 & $0.6520 \pm 0.0052$ & 15 & $0.5231 \pm 0.0098$ & 8 \\
\hline 8 & $0.4442 \pm 0.0072$ & 73 & $0.3099 \pm 0.0060$ & 67 & $0.6383 \pm 0.0071$ & 62 & $0.5159 \pm 0.0127$ & 70 \\
\hline 9 & $0.4505 \pm 0.0041$ & 65 & $0.2926 \pm 0.0064$ & 8 & $0.6309 \pm 0.0078$ & 8 & $0.5630 \pm 0.0158$ & 2 \\
\hline 10 & $0.4416 \pm 0.0075$ & 26 & $0.2987 \pm 0.0060$ & 33 & $0.6348 \pm 0.0065$ & 62 & $0.4954 \pm 0.0130$ & 31 \\
\hline 11 & $0.4468 \pm 0.0025$ & 222 & $0.3085 \pm 0.0043$ & 31 & $0.6354 \pm 0.0050$ & 27 & $0.5175 \pm 0.0066$ & 25 \\
\hline 12 & $0.4521 \pm 0.0032$ & 21 & $0.3015 \pm 0.0026$ & 20 & $0.6479 \pm 0.0032$ & 21 & $0.5064 \pm 0.0054$ & 19 \\
\hline 13 & $0.4484 \pm 0.0062$ & 47 & $0.3048 \pm 0.0113$ & 6 & $0.6376 \pm 0.0091$ & 12 & $0.5470 \pm 0.0135$ & 9 \\
\hline 14 & $0.4548 \pm 0.0041$ & 46 & - & - & - & - & - & - \\
\hline 15 & $0.4480 \pm 0.0083$ & 8 & $0.3016 \pm 0.0090$ & 4 & $0.6217 \pm 0.0116$ & 4 & $0.4642 \pm 0.0195$ & 4 \\
\hline 16 & $0.4627 \pm 0.0076$ & 4 & $0.2962 \pm 0.0063$ & 4 & $0.6563 \pm 0.0084$ & 3 & $0.5176 \pm 0.0136$ & 2 \\
\hline 17 & $0.4634 \pm 0.0250$ & 5 & $0.3254 \pm 0.0181$ & 6 & $0.6971 \pm 0.0314$ & 6 & $0.4623 \pm 0.0429$ & 3 \\
\hline 18 & $0.4510 \pm 0.0046$ & 196 & $0.3060 \pm 0.0079$ & 26 & $0.6386 \pm 0.0084$ & 28 & $0.5317 \pm 0.0104$ & 31 \\
\hline 19 & $0.4460 \pm 0.0106$ & 14 & $0.2851 \pm 0.0142$ & 5 & $0.6015 \pm 0.0183$ & 4 & $0.5256 \pm 0.0339$ & 4 \\
\hline 20 & $0.4627 \pm 0.0095$ & 6 & - & - & - & - & - & - \\
\hline 21 & $0.4470 \pm 0.0108$ & 3 & - & - & - & - & - & - \\
\hline 22 & $0.4639 \pm 0.0124$ & 7 & - & - & - & - & $0.5269 \pm 0.0213$ & 7 \\
\hline 23 & $0.4453 \pm 0.0137$ & 6 & - & - & - & - & - & - \\
\hline 24 & $0.4544 \pm 0.0042$ & 12 & - & - & - & - & - & - \\
\hline 26 & $0.4378 \pm 0.0058$ & 8 & $0.3008 \pm 0.0051$ & 6 & $0.6396 \pm 0.0062$ & 6 & $0.5152 \pm 0.0095$ & 6 \\
\hline w. avg & $0.4511 \pm 0.0011$ & 945 & $0.3018 \pm 0.0013$ & 310 & $0.6409 \pm 0.0016$ & 333 & $0.5135 \pm 0.0024$ & 286 \\
\hline SD & 0.011 & - & 0.011 & - & 0.018 & - & 0.024 & - \\
\hline
\end{tabular}

Notes. Note the larger standard deviation for the samples further from the calibration triangle defined by the anchors. The average $\Delta_{47}$ values for individual analytical sessions are reported in Table 2.

equal to $(0.5470-0.5135) / 0.0135=+2.48$. If the analytical errors reported in Table 3 are reasonably accurate, we expect the population of sigma-deviations among all laboratories to be distributed as the canonical Gaussian distribution $(\mu=0 ; \sigma=1)$, and we can test this prediction using established statistical methods such as a Kolmogorov-Smirnov test of normality (Massey, 1951). We carried out this test for two cases: only considering the error of sample replication (Figure 5, upper row) and second including the normalization error (i.e., the fully propagated error (Figure 5, lower row). If we neglect uncertainties arising from standardization (the "allogenic" errors of Daëron, 2021), the sigma-deviations are no longer normally distributed ( $p=0.003$, Figure 5 upper-left panel). When considering fully propagated analytical errors, as shown in the lower-left panel of Figure 5, the distribution of sigma-deviations for all laboratories and all samples is statistically indistinguishable from the expected normal distribution $(p=0.19)$. Figure 5 also illustrates that neglecting standardization errors does not strongly affect the normality of sigma-deviations for IAEA-C1, which has $\delta^{47}$ and $\Delta_{47}$ values within the range covered by the three anchor samples. By contrast, sigma-devi- 

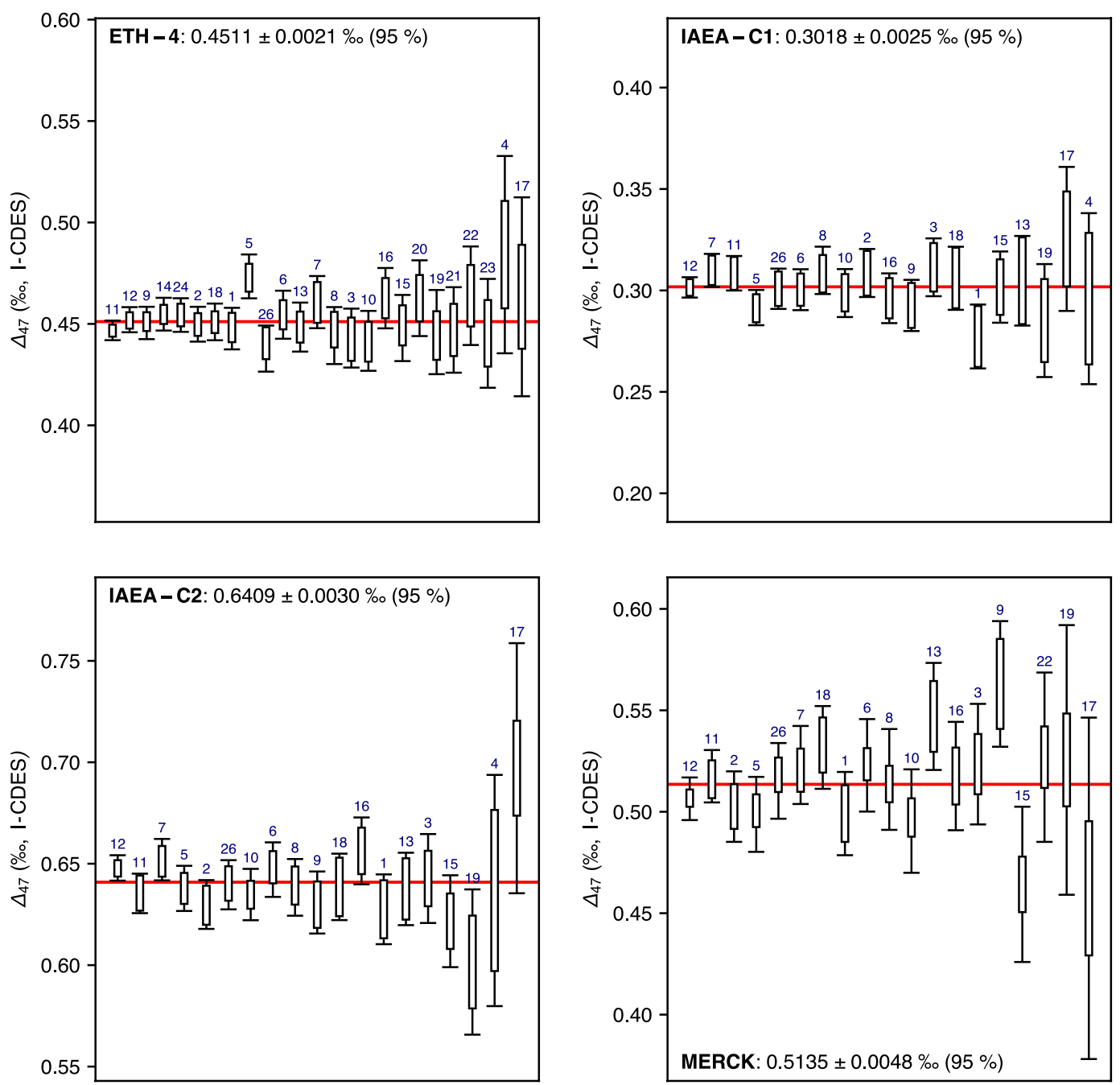

Figure 4. Final InterCarb results by laboratory. Error bars correspond to fully propagated $95 \%$ confidence limits, taking into account errors in both unknown and anchor analyses. Boxes correspond to 95\% confidence limits not accounting for normalization errors (i.e., only taking into account errors in unknown analyses). Results are sorted by increasing analytical errors, and laboratories are identified by number. Overall error weighted average $\Delta_{47}$ values are displayed as solid red lines and reported in each panel. All plots have the same vertical scale.

ations for unknowns with "exotic" isotopic compositions (ETH-4 and IAEA-C2 but especially MERCK) are only normally distributed if standardization uncertainties are correctly accounted for.

Based on these tests, we conclude that the interlaboratory scatter observed in the InterCarb data set is neither smaller nor larger than expected from the analytical uncertainties computed within each laboratory, as long as standardization errors are taken into account. This important finding implies that, at least for the time being, we can rule out any systematic interlaboratory discrepancies in carbonate-standardized $\Delta_{47}$ measurements, which constitutes an important milestone in the progress of clumped isotope measurement techniques.

On demonstrating that we can fully account for interlaboratory error using carbonate standardization, we revisit the results obtained for ETH1-4 using HG and EG (Figure 2). Applying the same Kolmogorov-Smirnov test of normality yields unambiguous evidence that the interlaboratory scatter observed here, using HG/EG standardization, is significantly greater than predicted from known analytical errors alone ( $p=0.005$, Figure 6 ), contrary to the opposite finding for the InterCarb results, using carbonate-based standardization ( $p=0.19$, Figure 5$)$. 
All samples
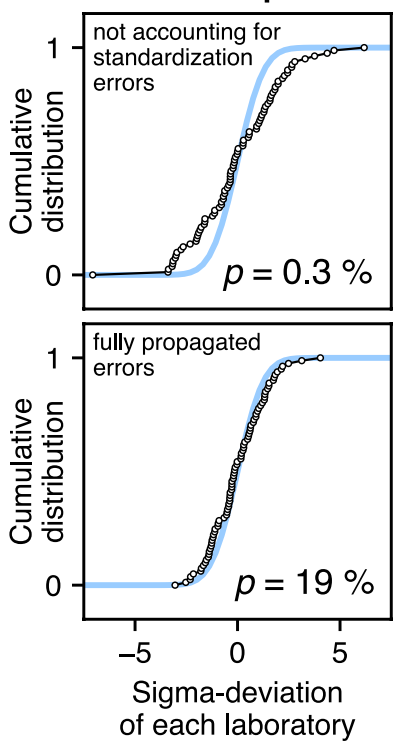

ETH-4
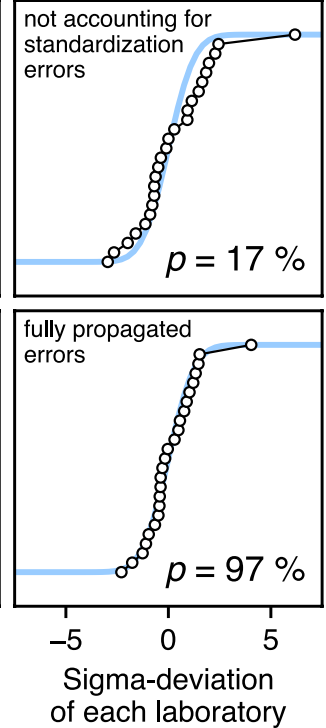

IAEA-C1
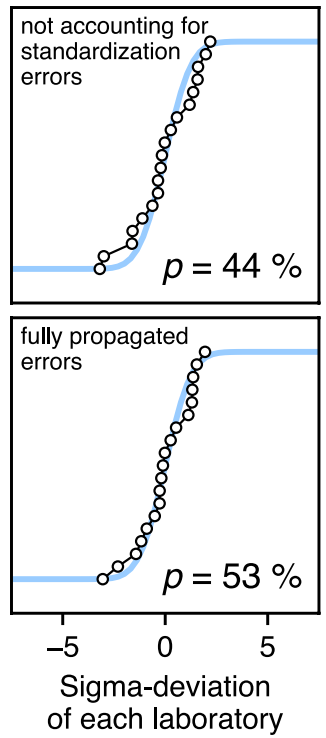

IAEA-C2

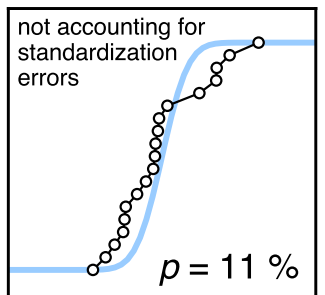

fully propagated

errors

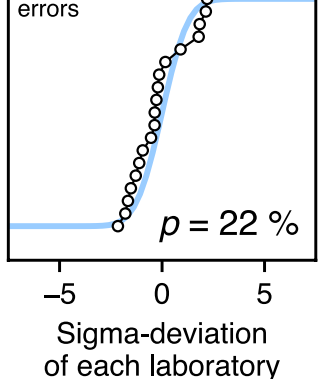

MERCK

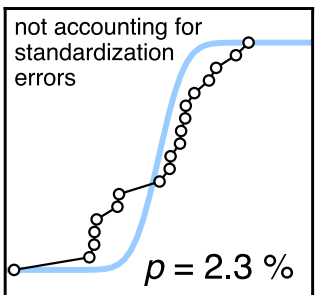

fully propagated

errors

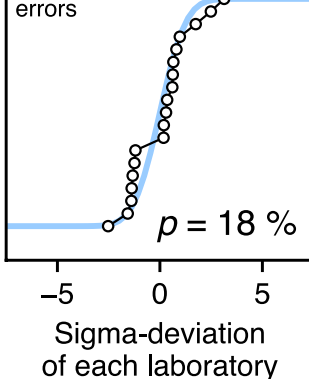

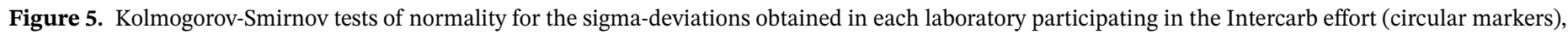
either neglecting standardization uncertainty (upper row) or considering fully propagated analytical errors (lower row). Lower-right corner Kolmogorov-

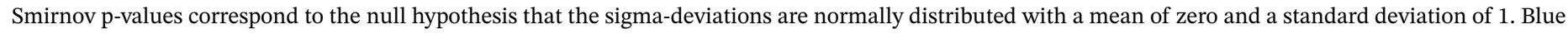
lines correspond to the canonical Gaussian distribution $(\mu=0 ; \sigma=1)$.

\subsection{Effects of Acid Reaction Temperature and IRMS Models}

Out of 25 sample preparation systems, 10 convert samples to $\mathrm{CO}_{2}$ by acid reactions at $70{ }^{\circ} \mathrm{C}$ and 14 at $90{ }^{\circ} \mathrm{C}$. To test for the possible effect of acid temperature, a commonly discussed cause for different slopes in the published temperature calibration curves (Came et al., 2014; Fernandez et al., 2014; Swart et al., 2019), we plot the $\Delta_{47}$ values of unknowns obtained by laboratories reacting at $70{ }^{\circ} \mathrm{C}$ versus those obtained at $90{ }^{\circ} \mathrm{C}$
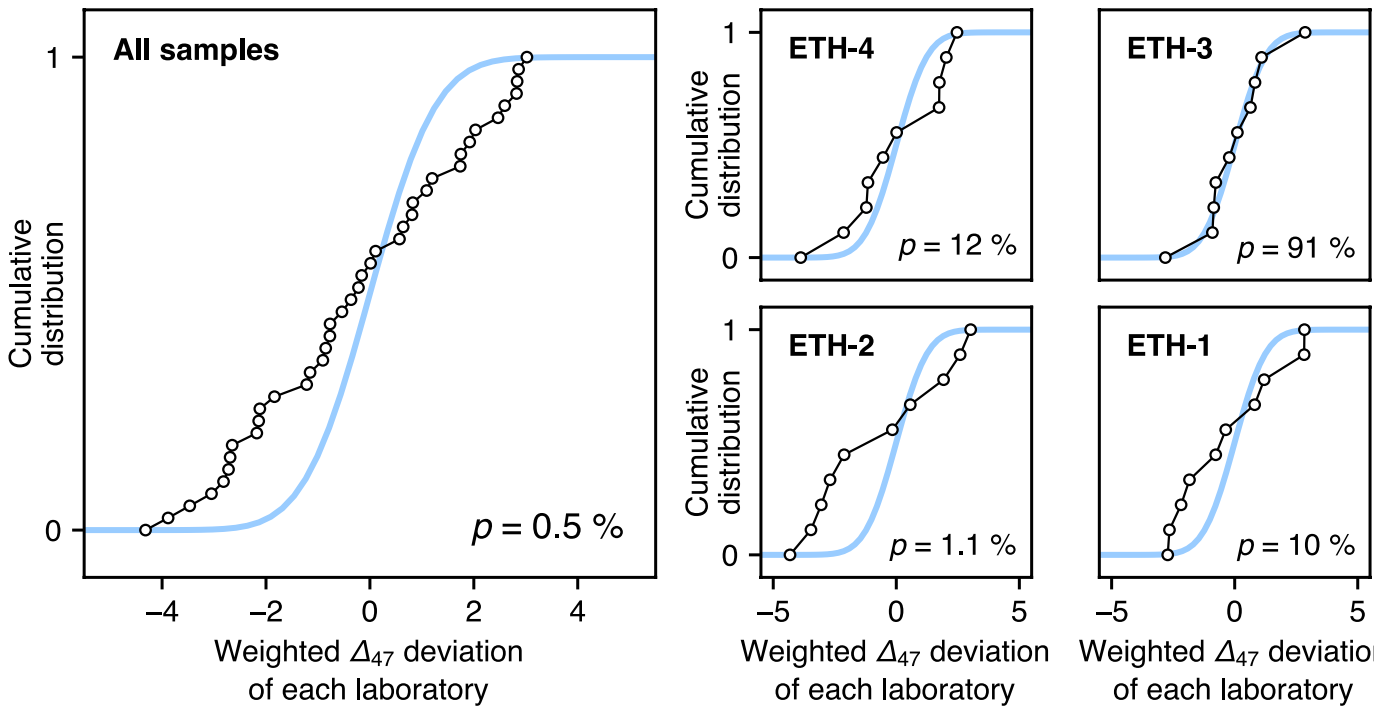

Weighted $\Delta_{47}$ deviation of each laboratory

Figure 6. Kolmogorov-Smirnov tests of normality for the sigma-deviations, considering fully propagated analytical errors (accounting for uncertainties associated with conversion to the CDES reference frame), obtained in each laboratory participating in the ETH-1/2/3/4 determination using HG and EG (circular markers). Lower-right corner Kolmogorov-Smirnov $p$-values correspond to the null hypothesis that the sigma-deviations are normally distributed with a mean of zero and a standard deviation of 1 . Blue lines correspond to the canonical Gaussian distribution $(\mu=0$; $\sigma=1)$. CDES, Carbon Dioxide Equilibrium Scale. 


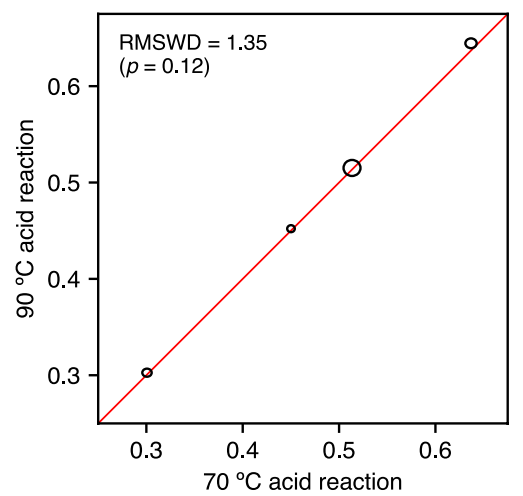

Figure 7. Error-weighted average $\Delta_{47}$ (I-CDES) values of unknowns obtained from acid reactions at $90^{\circ} \mathrm{C}$ versus $70{ }^{\circ} \mathrm{C}$. Solid black ellipses correspond to $95 \%$ confidence limits (see also Table 4). I-CDES, IntercarbCarbon Dioxide Equilibrium Scale.
(Figure 7, Table 4). Because acid fractionation effects equally affect anchors and unknowns, carbonate-standardized results can be compared directly without acid temperature correction. $\Delta_{47}$ values averaged by acid temperature are statistically indistinguishable for all of the unknowns. This implies that relative $\Delta_{47}$ differences between $\mathrm{CO}_{2}$ evolved from different samples are independent of acid reaction temperature within the range of experimental conditions covered here, and for a very wide range of $\Delta_{47(\mathrm{I}-\mathrm{CDES})}$ values spanning $0.302 \%$ (marbles) to $0.641 \%$ o (carbonates formed at ambient temperatures).

The error-weighted results separated by mass spectrometer type and design of associated preparation lines, another postulated source of interlaboratory disagreement (Swart et al., 2019), are shown in Figure 8 and Table 5. Out of the 22 participating laboratories, 8 use the Nu Perspective, 16 use versions of the Thermo MAT253, and one uses an Isoprime 100. Most results are statistically indistinguishable across instruments. Only IAEA-C2 yielded a significantly $(>2 \sigma)$ higher mean $\Delta_{47}$ value when measured on the Isoprime $100\left(\Delta \Delta_{47}\right.$ of +0.0110 and $+0.0081 \%$ o vs. $\mathrm{Nu}$ perspective and MAT253, respectively); but note that all of the Isoprime 100 data come from a single laboratory. Interinstrument differences averaged over all four samples (bottom row of Table 4) remain, however, indistinguishable from zero. Thus, any potential biases introduced by the use of different mass spectrometer models and/or the design of the preparation line which could cause partial equilibration of the produced $\mathrm{CO}_{2}$ with the acid and/or heated metal surfaces (Swart et al., 2019) are undetectable when using carbonate standardization. Sample sizes used for individual measurements ranged from 90 to $120 \mu \mathrm{g}$ for the Kiel IV to $\sim 500 \mu \mathrm{g}$ for the NuCarb individual acid vial preparation systems, and to 3-12 $\mathrm{mg}$ for samples reacted in common acid bath custom-built extraction lines. The fact that small sample measurements are carried out at $70^{\circ} \mathrm{C}$ and large ones at $90^{\circ} \mathrm{C}$, also suggests that there is no significant effect of sample sizes and variations in sample to acid ratios in these results.

\subsection{Guidelines for Minimizing Uncertainties in Clumped Isotope Analyses}

The results of InterCarb strongly support the use of carbonate standardization for clumped isotope measurements and show that it is possible to reach excellent data quality and interlaboratory consistency with instrumentation from all manufacturers and with both custom-built and commercially available sample preparation systems.

When considering all laboratories, the standard deviation of the averages for the four unknowns range from $0.011 \%$ o for ETH-4 to $0.024 \%$ o for MERCK. The spread is still relatively large, and not significantly better than that obtained by HG-EG normalization if we consider either what has been reported on four carbonate standards for four laboratories in Dennis et al. (2011) or the scatter in the values reported by the 10 laboratories that provided data for the re-determination of the accepted values of ETH-1 to ETH-3 in this study. However, we can clearly state that the large scatter is dominated by random errors and is especially influenced by the laboratories with the largest errors in the individual sample reproducibility and a significantly

Table 4

Error-Weighted Average $\Delta_{47}(I-C D E S)$ Values (\%o; $\left.\pm 1 S E\right)$ for Each Unknown as a Function of Acid Reaction Temperature (See Also Figure 7)

\begin{tabular}{lccc}
\hline & $\Delta_{47 \text { (I-CDES })}\left(70{ }^{\circ} \mathrm{C}\right.$ reaction $)$ & $\Delta_{47 \text { (I-CDES })}\left(90{ }^{\circ} \mathrm{C}\right.$ reaction $)$ & Difference $( \pm 1 \mathrm{SE})$ \\
\hline ETH-4 & $0.4501 \pm 0.0016$ & $0.4521 \pm 0.0015$ & $0.0020 \pm 0.0022$ \\
IAEA-C1 & $0.3006 \pm 0.0020$ & $0.3026 \pm 0.0017$ & $0.0020 \pm 0.0026$ \\
IAEA-C2 & $0.6369 \pm 0.0024$ & $0.6445 \pm 0.0021$ & $0.0076 \pm 0.0032$ \\
MERCK & $0.5134 \pm 0.0036$ & $0.5151 \pm 0.0034$ & $0.0017 \pm 0.0049$ \\
Average (all samples) & - & - & $0.0033 \pm 0.0017$ \\
\hline
\end{tabular}



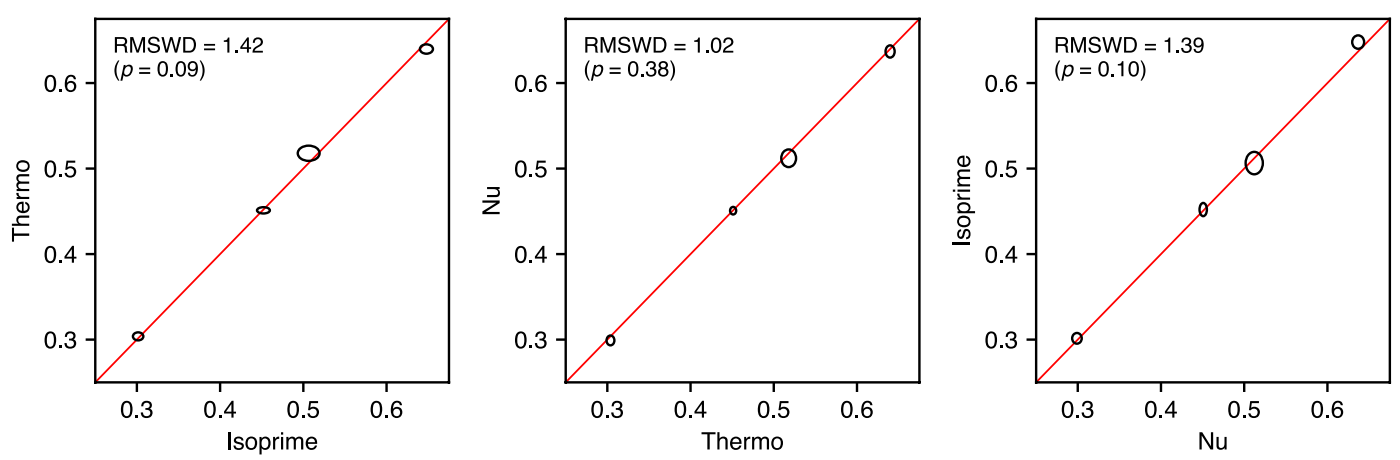

Figure 8. Error-weighted average $\Delta_{47}$ (I-CDES) values of unknowns obtained using different mass spectrometer types. Solid black ellipses correspond to 95\% confidence limits. I-CDES, Intercarb-Carbon Dioxide Equilibrium Scale.

magnified normalization error induced by a small number of replicates of anchors (Figure 4). Based on these observations we present strategies to improve the repeatability within each laboratory.

If we consider only laboratories with reported errors $<0.010 \%$ o (1SE) which is a desirable goal for the application of clumped isotopes in paleoclimate reconstructions, the standard deviation of the result is $\leq 0.009 \%$ o for the samples with no or moderate extrapolation from the compositional triangle defined by the anchors. This correspond to uncertainties across laboratories of approximately $3{ }^{\circ} \mathrm{C}$ at ambient temperatures. The laboratories with the smallest errors are those that generally analyzed a large number of samples and standards, as seen by the smaller 95\% CL errors and the small increase of the error when the normalization error is included (Figure 4). This observation underscores the necessity of sufficient replication to produce data of the quality that is required for meaningful interpretations. The number of necessary replicates to reach a target temperature uncertainty can be reduced by improving the external reproducibility of the measurements (see also Bonifacie et al., 2017; Daëron, 2021; Fernandez et al., 2017; Kocken et al., 2019).

Spreading replicate sample measurements in time and over multiple analytical sessions should help avoid analytical biases. The number and distribution of standards in a measuring interval are also important parameters to improve reproducibility and reduce errors. This has been discussed in detail by Kocken et al. (2019) and Daëron (2021) who both concluded that carbonate standards with bulk and clumped-isotope compositions similar to those of unknowns should be analyzed with greater frequency than the other anchors, while preserving a minimal level of replication for each anchor. In this study, analyses were grouped in measurement intervals, and all data were processed assuming no short-term variation in the instrumentation. However, especially with "small sample approaches" (e.g., the Kiel device) relying on short ( 30-45 $\mathrm{min}$ ) measurements of many replicates, one can observe short-term variations (e.g., Bernasconi et al., 2018, Figure 4). Thus a moving window correction with variable window size may be desirable in these cases, likely calling for specific error propagation procedures which remain yet to be defined.

Two important outcomes of this study are that acid reaction temperature and instrument and preparation line design are not a cause for differences among laboratories when standardization is based on carbonates. The lack of resolvable differences observed in our data set indicates that if preparation line differences

Table 5

Error-Weighted Average $\Delta_{47(-C D E S)}$ Differences $( \pm 1 S E)$ for Each Unknown as a Function of Mass Spectrometer Type

\begin{tabular}{lccc}
\hline & MAT 253 versus Isoprime 100 & Nu perspective versus MAT 253 & $\begin{array}{c}\text { Isoprime 100 versus } \\
\text { Nu perspective }\end{array}$ \\
\hline ETH-4 & $-0.0009 \pm 0.0035$ & $-0.0004 \pm 0.0024$ & $0.0013 \pm 0.0036$ \\
IAEA-C1 & $0.0023 \pm 0.0032$ & $-0.0048 \pm 0.0030$ & $0.0025 \pm 0.0035$ \\
IAEA-C2 & $-0.0081 \pm 0.0039$ & $-0.0029 \pm 0.0037$ & $0.0110 \pm 0.0043$ \\
MERCK & $0.0115 \pm 0.0065$ & $-0.0059 \pm 0.0056$ & $-0.0056 \pm 0.0068$ \\
Average (all samples) & $0.0012 \pm 0.0022$ & $-0.0035 \pm 0.0019$ & $0.0023 \pm 0.0024$ \\
\hline
\end{tabular}


affect $\Delta_{47}$ measurements, standardization with carbonates corrects any such effects whereas HG-EG standardization may fail to do so (Swart et al., 2019). Thus, when using carbonate standardization, these factors can be ignored provided the carbonate standards cover a large range in $\Delta_{47}$. Thus, following the principle of identical treatment of samples and standards (Werner \& Brand, 2001) clearly reduces uncertainties compared to the use of HG/EG standardization. We have to consider, however, that acid digestion conditions (e.g., reaction times, temperatures) and the temperature dependence of phosphoric acid fractionation (Defliese et al., 2015; Murray et al., 2016; van Dijk et al., 2019) may differ with carbonate mineralogy, therefore possible effects on $\Delta_{47}$ could be mineral-specific. For this reason, it would be highly desirable to produce reference materials for dolomite, aragonite, magnesite and siderite. For dolomite, three samples were proposed by Müller et al. (2019) as possible reference materials and are available upon request. Ideally it would also be desirable to anchor the measurements in a carbonate absolute reference frame by creating some carbonates with independently known clumped isotope compositions.

For InterCarb, all distributed aliquots of IAEA-C1, IAEA-C2, and MERCK originated from single bottles. The IntrCarb results suggest that after milling, these carbonates were homogeneous within these bottles, but we strongly recommend verifying that additional bottles purchased from IAEA and MERCK are identical to the ones tested here. Nishida and Ishimura (2017) found that IAEA 603, which was produced from the same coarse marble as IAEA-C1, contained a minor mount of grains with different isotopic composition, thus it is recommended to thoroughly mill and homogenize IAEA-C1 before use, especially for use in small-sample preparation systems. Merk and ETH-4 are both very fine grained synthetic calcium carbonates, and it has been suggested that the oxygen isotope composition of such fine-grained carbonates could change with time due to exchange with atmospheric $\mathrm{CO}_{2}$ (Qi et al., 2021). At the ETH laboratory different aliquots of ETH-4 have been in use since 2013 and no alterations of its oxygen or clumped isotope composition were observed. However we strongly recommend that all standards are stored in a desiccator to reduce the chance of alteration.

Standardization errors could be reduced to some extent by increasing the range of bulk composition of the anchor samples (e.g., as illustrated by Figure 1 of Daëron, 2021), especially when samples are measured that require significant extrapolation. A sample with an extreme bulk composition like MERCK would be a useful addition as an anchor, regardless of its $\Delta_{47}$ value. While with a three-anchor system, two heated standards for normalization are not strictly necessary, a "heated MERCK" anchor in combination with ETH-1 would furthermore allow verifying the PBL correction with greater confidence and with less replication than with ETH-2 (keeping in mind that small quadratic components to PBL correction might introduce a significant bias over a $\delta^{47}$ range of $60 \%$, e.g., Figure 7 from He et al., 2012).

With InterCarb, the nominal values of the ETH standards are robustly linked to the CDES, as they are now based on the average results of 10 laboratories, and are not only based on the values determined at ETH in 2013. Some laboratories may still want to continue measuring HG and EG to keep established laboratory procedures and/or to cover ranges in bulk compositions that require large extrapolations. However, the results of InterCarb, and the discussions in the literature (e.g., Petersen et al., 2019) show that with the HG/EG approach there are still poorly understood interlaboratory discrepancies (as suggested by Figure 6) which are absent in the carbonate-based normalization (see Figure 5). For this reason, it is of paramount importance that several of the InterCarb reference carbonates are incorporated in the laboratory procedures to ensure interlaboratory data compatibility. The use of matrix-matched reference materials is necessary so that delta values can be unambiguously compared on a like-for-like basis (see Meier-Augenstein \& Schimmelmann, 2019 for a recent discussion).

For laboratories using large sample common-acid bath methodologies and preferring gas-based data correction, we recommend that in addition to HG/EG a minimum of two of the InterCarb reference materials (or in-house standards with values calibrated to ETH standards) should be measured within the same analytical sessions as the samples and used in the data correction scheme. We recommend choosing two standards with a large difference in $\Delta_{47}$, for example, ETH-1 and ETH-3 or ETH-2 and IAEA-C2, depending on the bulk composition of the unknown samples (see Figure 1). In the case of samples with very low $\delta^{47}$ values, we additionally recommend the use of MERCK. 
For laboratories with commercially available single acid vial, small sample preparation systems, we discourage the use of HG/EG, as the gases would most probably be measured under different conditions than the samples, an approach which is prone to error. In addition, InterCarb shows that carbonate-based standardization can provide robust and accurate data without the use of gases.

Achieving the best possible reproducibility and accuracy is especially important when reconstructing small temperature changes for the reconstruction of climate change and/or the study of high temperature processes where the sensitivity of the clumped isotope thermometer is low. We emphasize that the improvements in interlaboratory comparability that can be achieved with carbonate standardization, coupled with the reductions in the uncertainties of the temperature calibrations (e.g., Anderson et al., 2021), is decreasing the uncertainties in temperature reconstructions to levels comparable or better than other temperature proxies.

\subsection{Reporting Data Normalized to Carbonates: Definition of the I-CDES}

There is a need for a community consensus on how to report clumped isotope measurements, both to promote data comparability and to reduce confusion stemming from the different scales used in the literature. Currently $\Delta_{47}$ data are reported for different temperatures of phosphoric acid digestion, mostly projected to $25{ }^{\circ} \mathrm{C}$ but also to $70{ }^{\circ} \mathrm{C}$ or $90{ }^{\circ} \mathrm{C}$ reactions, and generally labeled respectively as $\Delta_{47 \mathrm{CDES} 25}, \Delta_{47 \mathrm{CDES} 70}$, and $\Delta_{47 \mathrm{CDES} 90}$, a terminology introduced in Bonifacie et al. (2017). In the literature, phosphoric acid correction factors used by different research groups to convert results from $90{ }^{\circ} \mathrm{C}$ to $25{ }^{\circ} \mathrm{C}$ reaction temperatures have varied between $0.069 \%$ (Wacker et al., 2014) and 0.092\%o (e.g., Bonifacie et al., 2017), thus representing a significant source of uncertainty and confusion.

The direct standardization to accepted values of solid phases, on the other hand, removes the need for a phosphoric acid correction, yielding results which are independent of the temperature at which the samples were reacted. In InterCarb this has only been tested for calcites, the mineralogy of all standards used here. Further studies are necessary in particular for dolomite and siderite, as these minerals require longer reaction times and there are contrasting findings in the literature on whether they require different phosphoric acid fractionations (Bonifacie et al., 2017; Müller et al., 2019; Petersen et al., 2019; van Dijk et al., 2019), possibly affecting the absolute values of samples with such mineralogies. Aragonite may also have a different phosphoric acid fractionation factor than calcite (Müller, Violay, et al., 2017). Nevertheless, the use of the InterCarb reference carbonates, allows for a consistent correction of instrumental effects and normalization to the I-CDES, independent of the mineralogy. Possible effects related to the longer reaction time remain to be tested, and require intercomparison samples of different mineralogy. In any case, for all calcites, carbonate standardization eliminates different phosphoric acid correction factors as a source of uncertainty and provides a consistent framework to report $\Delta_{47}$ without uncertainties related to the reaction temperature.

For these reasons, we recommend that in the future, carbonate clumped isotope values should be reported relative to a carbonate reference frame uniquely defined by the absolute $\Delta_{47}$ values reported in Table 1 for ETH-1, ETH-2, and ETH-3. Unknown samples may be anchored to this reference frame either (a) directly by comparison to ETH-1/2/3, (b) indirectly by comparison with several of the four other carbonate standards used here (Figure 4), or (c) by comparison with a set of in-house laboratory standards whose composition is well-constrained relative to the materials reported here. To clearly distinguish this data normalization scheme from previous ones the denomination I-CDES should be use, with the notation $\Delta_{47(\mathrm{I}-\mathrm{CDES})}$. This approach is analogous to the change from the PDB to the VPDB scale, which was accomplished by assigning a consensus offset of $+1.95 \%$ o between the original PDB reference material and the NBS19 carbonate. This was subsequently, albeit temporarily, improved by defining a second anchor point with the L-SVEC lithium carbonate standard (Coplen et al., 2006). We note that because the carbonate $\Delta_{47}$ values in Table 1 are firmly anchored to the CDES scale via HG/EG measurements in multiple laboratories, the two scales are in principle equivalent. However, I-CDES has three major advantages: (1) it follows the principle of equal treatment of sample and standards; (2) it removes uncertainties related to fractionation effects due to different acid reaction temperatures and designs of the preparation lines; and (3) it is based on traceable, stable materials (calcium carbonates) that are widely available to interested laboratories. Furthermore, the results summarized in Figure 5 imply that I-CDES standardization yields consistent $\Delta_{47}$ values independent of laboratory and/or analytical protocols, so that interlaboratory scatter is accurately predicted by the 
fully propagated analytical uncertainties computed within each laboratory. By contrast, this does not always seem to be the case for gas-based standardization to the CDES reference frame (Figure 6), suggesting the existence of poorly understood sources of interlab discrepancies in that approach. The broad availability of carbonate reference materials with widely varying bulk and clumped isotope compositions is an important step to help establish a worldwide equivalence among laboratories and help new laboratories establish and verify their analytical procedures.

\subsection{Comparability With Previously Published Data}

The decision that $\Delta_{47(\mathrm{I}-\mathrm{CDES})}$ values are reported for an acid reaction temperature of $90{ }^{\circ} \mathrm{C}$ implies that the I-CDES value of any given sample will be almost $0.1 \%$ o lower than its $\Delta_{47 \mathrm{CDES} 25}$ values which is currently the most common convention used to report clumped isotopes. At first sight it may seem a disadvantage to lose the ability to intuitively compare new results to those obtained through different standardization approaches in the published literature. However, it will make it immediately obvious that I-CDES-normalized values cannot directly be compared to data standardized to the ETH-1/2/3/4 values reported by Bernasconi et al. (2018).

To directly compare previous carbonate-normalized $\Delta_{47}$ values and the already published calibration equations produced with ETH standard normalization (Bernasconi et al., 2018; Jautzy et al., 2020; Kele et al., 2015; Meinicke et al., 2020; Peral et al., 2018; Piasecki et al., 2019) to data reported on the I-CDES scale, previous data have to be recalculated as described in detail in the Appendix A. We emphasize again, however, that the temperatures calculated from the original calibrations using the original ETH standard values are directly comparable to temperatures calculated for samples normalized and calibrations recalculated to the I-CDES. This is because only the nominal values of the standards have changed, and thus the data normalization is internally consistent and traceable to the same solid standards.

In principle, I-CDES data are directly comparable to data produced by phosphoric acid reaction at $90{ }^{\circ} \mathrm{C}$ using the HG/EG approach, with the important caveat that in absence of measurements of widely available carbonates, a direct comparison remains uncertain, especially for older data. A community effort to robustly anchor the composition of legacy standards measured in the original laboratories, may alleviate this problem in the near future.

\section{Conclusions}

- This study demonstrates that carbonate-based standardization of clumped isotope measurements solves many open questions that so far limited the application of carbonate clumped isotope thermometry as a mature and reliable tool in Earth sciences

- Interlaboratory discrepancies among 22 laboratories observed in this study are not greater than those predicted from intralaboratory analytical uncertainties

- We propose a set of two high-purity carbonate reagents and five widely available calcite reference materials for normalization of carbonate clumped isotope measurements with new community-accepted values: the four ETH standards, two samples distributed by the IAEA (C1 and C2), and a synthetic carbonate produced by MERCK. The ETH standards are available upon request from S. M. Bernasconi

- Carbonate standardization removes the need to apply an acid digestion fractionation factor, eliminating uncertainties due to poorly known acid fractionation factors and different preparation systems and thus reduces differences between laboratories

- In principle, data expressed in the I-CDES are directly comparable to samples reacted at a temperature of $90{ }^{\circ} \mathrm{C}$ normalized to the classical CDES with HG/EG. However, we emphasize that carbonate standardization is preferred to pure HG/EG normalization because it is based on traceable carbonate samples that can be measured in every laboratory. Reporting the measured compositions of carbonate reference materials together with the samples is the only way to ensure interlaboratory consistency

- Robust standardization of clumped isotope measurements requires the analysis of a sufficient number of replicates of both samples and standard materials (either gases or carbonates) alongside unknowns to minimize error and obtain accurate measurements within a single laboratory 


\section{Appendix A: Converting Older, Carbonate-Anchored $\Delta$ Values to the I-CDES}

This section describes the steps necessary to convert existing $\Delta_{47}$ measurements to the I-CDES, provided that they were either standardized using carbonate anchors or analyzed simultaneously with several carbonate anchors. This mathematically exact approach is a simpler alternative to fully reprocessing the original raw data (with the caveat that this conversion will not provide, by itself, any error estimates).

By way of example, let us consider measurements originally standardized using ETH-1/2/3 with the nominal $\Delta_{47}$ values reported by Bernasconi et al. (2018). The "old" $\Delta_{47}$ values of these measurements are noted $\Delta_{47}^{\text {old }}$, and we wish to compute the "new" $\Delta_{47}$ values, noted $\Delta_{47}^{\text {new }}$, that would be obtained if the same data were standardized to the I-CDES.

Both old and new $\Delta_{47}$ values are derived from the same set of raw measurements using "linear" (more accurately: affine) transformations of the form:

$$
\begin{gathered}
\Delta_{47}^{\text {old }}=x_{1}+y_{1} \delta^{47}+z_{1} \Delta_{47}^{\text {raw }} \\
\Delta_{47}^{\text {new }}=x_{2}+y_{2} \delta^{47}+z_{2} \Delta_{47}^{\text {raw }}
\end{gathered}
$$

We can rearrange the above equations to express $\Delta_{47}^{\text {new }}$ as a function of $\delta^{47}$ and $\Delta_{47}^{\text {old }}$ :

$$
\Delta_{47}^{\text {new }}=a+b \delta^{47}+c \Delta_{47}^{\text {old }}
$$

Computing the numerical values of $(a, b, c)$ is thus all that is required to compute $\Delta_{47}^{\text {new }}$ for any sample whose $\left(\delta^{47}, \Delta_{47}^{\text {old }}\right)$ values are known. This computation only requires knowing $\left(\delta^{47}, \Delta_{47}^{\text {old }}, \Delta_{47}^{\text {new }}\right)$ for three different anchors, for instance ETH-1/2/3. In matrix form, Equation A.3 then becomes:

$$
\begin{gathered}
\text { Thus: }\left(\begin{array}{lll}
1 & \delta_{(\mathrm{ETH} 1)}^{47} & \Delta_{47(\mathrm{ETH} 1)}^{\text {old }} \\
1 & \delta_{(\mathrm{ETH} 2)}^{47} & \Delta_{47(\mathrm{ETH} 2)}^{\text {old }} \\
1 & \delta_{(\mathrm{ETH} 3)}^{47} & \Delta_{47(\mathrm{ETH} 3)}^{\text {old }}
\end{array}\right)\left(\begin{array}{l}
a \\
b \\
c
\end{array}\right)=\left(\begin{array}{c}
\Delta_{47(\mathrm{ETH} 1)}^{\text {new }} \\
\Delta_{47(\mathrm{ETH} 2)}^{\text {new }} \\
\Delta_{47(\mathrm{ETH} 3)}^{\text {new }}
\end{array}\right) \\
\left(\begin{array}{l}
a \\
b \\
c
\end{array}\right)=\left(\begin{array}{lll}
1 & \delta_{(\mathrm{ETH} 1)}^{47} & \Delta_{47(\mathrm{ETH} 1)}^{\text {old }} \\
1 & \delta_{(\mathrm{ETH} 2)}^{47} & \Delta_{47(\mathrm{ETH} 2)}^{\text {old }} \\
1 & \delta_{(\mathrm{ETH} 3)}^{47} & \Delta_{47(\mathrm{ETH} 3)}^{\text {old }}
\end{array}\right)^{-1}\left(\begin{array}{l}
\Delta_{47(\mathrm{ETH} 1)}^{\text {new }} \\
\Delta_{47(\mathrm{ETH} 2)}^{\text {new }} \\
\Delta_{47(\mathrm{ETH} 3)}^{\text {new }}
\end{array}\right)
\end{gathered}
$$

In this example, the $\Delta_{47}^{\text {old }}$ and $\Delta_{47}^{\text {new }}$ values are the old and new nominal values of ETH- $1 / 2 / 3$. If the $\delta^{47}$ values are defined as usual by reference to a working gas, the parameters $(a, b, c)$ will vary when different working gases are used. However, the above equations remain valid if $\delta^{47}$ is defined instead by reference to a fixed, hypothetical $\mathrm{CO}_{2}$ composition, for example, stochastic VPDB- $\mathrm{CO}_{2}\left(\delta^{13} \mathrm{C}_{\mathrm{VPDB}}=0 ; \delta^{18} \mathrm{O}_{\mathrm{VSMOW}} \approx 41.5 \%\right.$; $\left.\Delta_{47}=0, R^{47}=4.834 \times 10^{-5}\right)$. In that case, numerical values of the parameters $(a, b, c)$ can be determined once and then used to compute $\Delta_{47}^{\text {new }}$ for any unknown sample based only on its $\Delta_{47}^{\text {old }}$ and $\delta^{47}$ values (the latter being defined relative to VPDB- $\mathrm{CO}_{2}$ and computed by applying an acid ${ }^{18} \mathrm{O} /{ }^{16} \mathrm{O}$ fractionation factor of 1.01025 to said sample). Importantly, this particular transformation applies to all data sets originally standardized in the reference frame defined by the "old" nominal values of ETH-1/2/3.

For instance, the relationship linking the ETH-1/2/3 reference frame of Bernasconi et al. (2018) to the I-CDES is defined by:

$$
\left(\begin{array}{l}
a \\
b \\
c
\end{array}\right)=\left(\begin{array}{lll}
1 & 0.010 & 0.258 \\
1 & -28.375 & 0.258 \\
1 & 0.538 & 0.691
\end{array}\right)^{-1}\left(\begin{array}{l}
0.2052 \\
0.2085 \\
0.6132
\end{array}\right)=\left(\begin{array}{l}
-0.037997 \\
-0.000182 \\
0.942590
\end{array}\right)
$$


Thus:

$$
\Delta_{47}^{\text {new }}=-0.038039-0.000183 \delta^{47}+0.942603 \Delta_{47}^{\text {new }}
$$

In this case, it is clear that the conversion from the old reference frame to the new one is not very sensitive to $\delta^{47}$ values: for unknown samples with $\delta^{47}$ values within $\pm 6 \%$ of ETH-1 (or stochastic VPDB-CO ${ }_{2}$ ), the effect of the second term in Equation A. 7 is less than 1 ppm, and less than 3 ppm for unknowns within $\pm 18 \%$ of ETH-1. In such cases, the conversion may be simplified as a simpler affine transformation, akin to a more traditional two-point normalization (e.g., VSMOW-VSLAP standardization):

$$
\Delta_{47}^{\text {new }}=0.942603 \Delta_{47}^{\text {old }}-0.038039
$$

For instance, to convert the $\Delta_{47}^{\text {old }}$ value of ETH-4 reported by Bernasconi et al. (2018) to the I-CDES, we only need to know that $\delta^{47}{ }_{\text {(ЕTH } 4)}=-28.8 \%$ and $\Delta_{47}^{\text {old }}=0.507 \pm 0.004 \%$. The $\Delta_{47}^{\text {new }}$ value predicted by Equation A.7 is then $0.445 \pm 0.004 \%$, to be compared with the independently constrained values reported here in Table 1 $(0.450 \pm 0.002 \%$ o $)$ and Table $3(0.451 \pm 0.001 \%$ o $)$

The above computation could also be performed using any arbitrary set of three carbonate materials whose $\left(\delta^{47}, \Delta_{47}^{\text {old }}, \Delta_{47}^{\text {new }}\right)$ values are known, provided that they span a wide enough range in $\delta^{47}$ and $\Delta_{47}$. This is true even if the carbonates in question were not originally used to standardize the raw data, as would be the case for $\mathrm{CO}_{2}$-standardized measurements. In the case where only two suitable carbonate standards $X$ and $Y$ are available, an acceptable approach would be to neglect $\delta^{47}$ effects (equivalent to setting the value of $b$ to zero in Equation A.3) by solving the following equation:

$$
\left(\begin{array}{l}
a \\
c
\end{array}\right)=\left(\begin{array}{ll}
1 & \Delta_{47(\mathrm{X})}^{\text {old }} \\
1 & \Delta_{47(\mathrm{Y})}^{\text {old }}
\end{array}\right)^{-1}\left(\begin{array}{c}
\Delta_{47(\mathrm{X})}^{\mathrm{new}} \\
\Delta_{47(\mathrm{Y})}^{\mathrm{new}}
\end{array}\right)
$$

\section{Data Availability Statement}

All data analyzed as part of this study, along with all code used to process them, are available at https:// github.com/mdaeron/InterCarb and http://doi.org/10.5281/zenodo.4314448

Acknowledgments

S. M. Bernasconi acknowledges instrumentation funding from ETH Zürich and support from Swiss National Science Foundation grants 200021_143485, 200020_160046. M. Daëron acknowledges the clumped-isotope facility at LSCE is part of PANOPLY (Plateforme Analytique Géosciences Paris-Saclay) and was supported by the following institutions: Région Ile-de-France; Direction des Sciences de la Matière du Commissariat à l'Energie Atomique; Institut National des Sciences de l'Univers, Centre National de la Recherche Scientifique; Universtité de Versailles/Saint-Quentin-en-Yvelines. K. D. Bergmann and the MIT carbonate clumped isotope facility acknowledge support from the Packard Foundation, the Agouron Foundation and NASA Exobiology Grant 80NSSC19K0464. M. Bonifacie acknowledges the program Emergences Ville de Paris for early funding that allowed building her clumped isotope laboratory at Institut de Physique du Globe de Paris. M. Bonifacie also thanks IPGP and Université

\section{References}

Adlan, Q., Davies, A. J., \& John, C. M. (2020). Effects of oxygen plasma ashing treatment on carbonate clumped isotopes. Rapid Communications in Mass Spectrometry, 34(14), e8802. https://doi.org/10.1002/rcm.8802

Affek, H. P., \& Eiler, J. M. (2006). Abundance of mass $47 \mathrm{CO} 2$ in urban air, car exhaust, and human breath. Geochimica et Cosmochimica Acta, 70(1), 1-12. https://doi.org/10.1016/j.gca.2005.08.021

Anderson, N. T., Kelson, J. R., Kele, S., Daëron, M., Bonifacie, M., Horita, J., et al. (2021). A unified clumped isotope thermometer calibration $\left(0.5-1100^{\circ} \mathrm{C}\right)$ using carbonate-based standardization. Geophysical Research Letters. https://doi.org/10.1029/2020GL092069

Bajnai, D., Guo, W., SpoetlCoplen, C. T. B., Methner, K., Löffler, N., Krsnik, E., et al. (2020). Dual clumped isotope thermometry resolves kinetic biases in carbonate formation temperatures. Nature Communications, 11, 4005. https://doi.org/10.1038/s41467-020-17501-0

Bernasconi, S. M., Hu, B., Wacker, U., Fiebig, J., Breitenbach, S. F. M., \& Rutz, T. (2013). Background effects on Faraday collectors in gassource mass spectrometry and implications for clumped isotope measurements. Rapid Communications in Mass Spectrometry, 27(5), 603-612. https://doi.org/10.1002/rcm.6490

Bernasconi, S. M., Müller, I. A., Bergmann, K. D., Breitenbach, S. F. M. M., Fernandez, A., Hodell, D. A., et al. (2018). Reducing uncertainties in carbonate clumped isotope analysis through consistent carbonate-based standardization. Geochemistry, Geophysics, Geosystems, 19(9), 1-20. https://doi.org/10.1029/2017gc007385

Bonifacie, M., Calmels, D., Eiler, J. M., Horita, J., Chaduteau, C., Vasconcelos, C., et al. (2017). Calibration of the dolomite clumped isotope thermometer from 25 to $350^{\circ} \mathrm{C}$, and implications for a universal calibration for all ( $\left.\mathrm{Ca}, \mathrm{Mg}, \mathrm{Fe}\right) \mathrm{CO} 3$ carbonates. Geochimica et Cosmochimica Acta, 200, 255-279. https://doi.org/10.1016/j.gca.2016.11.028

Brand, W. a., Assonov, S. S., \& Coplen, T. B. (2010). Correction for the $17 \mathrm{O}$ interference in $\delta(13 \mathrm{C})$ measurements when analyzing CO2 with stable isotope mass spectrometry (IUPAC Technical Report). Pure and Applied Chemistry, 82(8), 1719-1733. https://doi.org/10.1351/ pac-rep-09-01-05

Came, R. E., Brand, U., \& Affek, H. P. (2014). Clumped isotope signatures in modern brachiopod carbonate. Chemical Geology, 377, 20-30. https://doi.org/10.1016/j.chemgeo.2014.04.004

Carter, J. F., \& Fry, B. (2013). Ensuring the reliability of stable isotope ratio data-beyond the principle of identical treatment. Analytical and Bioanalytical Chemistry, 405(9), 2799-2814. https://doi.org/10.1007/s00216-012-6551-0

Coplen, T. B. (2011). Guidelines and recommended terms for expression of stable-isotope-ratio and gas-ratio measurement results. Rapid Communications in Mass Spectrometry, 25(17), 2538-2560. https://doi.org/10.1002/rcm.5129 
de Paris for support for the organization of the VIth Clumped Isotope Workshop in Paris in 2017. Funding was provided to C. M. John and the Imperial College Clumped Isotope Laboratory by Qatar Petroleum, Shell, and the Qatar Science and Technology Panel. Funding was provided to K. W. Huntington at University of Washington from NSF EAR grants 1933130, 1713275, and 1156134 . T. Vennemann acknowledges the support of the Swiss National Science Foundation grant 206021-164032. A. N. Meckler acknowledges funding from the Trond Mohn Foundation and the European Research Council (ERC) under the European Union's Horizon 2020 research and innovation program (grant agreement no. 638467). Funding was provided to the Tripati Laboratory at UCLA for these analyses from DOE BES grant DE-FG02-13ER16402. Funding was provided to the Hyland Laboratory at NCSU for these analyses from NSF EAR-FRES grant 1925973. Funding was provided to the Yoshida Laboratory at Tokyo Tech. for these analyses from JSPS grant JP17H06105. Funding was provided to the CLIMB Lab at the University of Bergen for these analyses by the European Research Council (ERC) under the European Union's Horizon 2020 research and innovation program (grant agreement No 638467) and by the Trond Mohn Foundation. Funding was provided to the UU Clumped Laboratory at Utrecht University by the Netherlands Research Organization (NWO) through VIDI grant 016.161.365. Funding was provided to the CUBES-SIL at CU Boulder by startup funds from the University of Colorado Boulder and NSF EAR grant 1524785. The UM SCIPP Laboratory was supported by startup funds from the University of Michigan. J. R. Kelson was supported by NSF PRF grant 1854873. HPA acknowledges support by ERC (Grant no.724097) and ISF (Grant no. 171/16 and 1000/16). Funding was provided to the Eiler lab at Caltech from the DOE BES program, award number DE-SC0016561.
Coplen, T. B., Brand, W. A., Gehre, M., Gröning, M., Meijer, H. A. J., Toman, B., \& Verkouteren, R. M. (2006). After two decades a second anchor for the VPDB 13 C scale. Rapid Communications in Mass Spectrometry, 20(21), 3165-3166. https://doi.org/10.1002/rcm.2727

Daëron, M. (2021). Full propagation of analytical uncertainties in $\Delta_{47}$ measurements. Geochemistry, Geophysics, Geosystems. https://doi. org/10.1029/2020GC009592

Daëron, M., Blamart, D., Peral, M., \& Affek, H. P. (2016). Absolute isotopic abundance ratios and the accuracy of $\Delta 47$ measurements. Chemical Geology, 442, 83-96. https://doi.org/10.1016/j.chemgeo.2016.08.014

Dale, A., John, C. M., Mozley, P. S., Smalley, P. C., \& Muggeridge, A. H. (2014). Time-capsule concretions: Unlocking burial diagenetic processes in the Mancos Shale using carbonate clumped isotopes. Earth and Planetary Science Letters, 394, 30-37. https://doi.org/10.1016/j. epsl.2014.03.004

Defliese, W. F., Hren, M. T., \& Lohmann, K. C. (2015). Compositional and temperature effects of phosphoric acid fractionation on $\Delta 47$ analysis and implications for discrepant calibrations. Chemical Geology, 396, 51-60. https://doi.org/10.1016/j.chemgeo.2014.12.018

Defliese, W. F., \& Lohmann, K. C. (2015). Non-linear mixing effects on mass-47 CO2 clumped isotope thermometry: Patterns and implications. Rapid Communications in Mass Spectrometry, 29(9), 901-909. https://doi.org/10.1002/rcm.7175

Dennis, K. J., Affek, H. P., Passey, B. H., Schrag, D. P., \& Eiler, J. M. (2011). Defining an absolute reference frame for 'clumped' isotope studies of CO2. Geochimica et Cosmochimica Acta, 75(22), 7117-7131. https://doi.org/10.1016/j.gca.2011.09.025

Eagle, R. A., Schauble, E. A., Tripati, A. K., Tütken, T., Hulbert, R. C., \& Eiler, J. M. (2010). Body temperatures of modern and extinct vertebrates from 13C-180 bond abundances in bioapatite. Proceedings of the National Academy of Sciences of the United States of America, 107(23), 10377-10382. https://doi.org/10.1073/pnas.0911115107

Fernandez, A., Müller, I. A., Rodríguez-Sanz, L., van Dijk, J., Looser, N., \& Bernasconi, S. M. (2017). A reassessment of the precision of carbonate clumped isotope measurements: Implications for calibrations and paleoclimate reconstructions. Geochemistry, Geophysics, Geosystems, 18(12). https://doi.org/10.1002/2017gc007106

Fernandez, A., Tang, J., \& Rosenheim, B. E. (2014). Siderite 'clumped' isotope thermometry: A new paleoclimate proxy for humid continental environments. Geochimica et Cosmochimica Acta, 126, 411-421. https://doi.org/10.1016/j.gca.2013.11.006

Ferry, J. M., Passey, B. H., Vasconcelos, C., \& Eiler, J. M. (2011). Formation of dolomite at $40-80^{\circ} \mathrm{C}$ in the Latemar carbonate buildup, Dolomites, Italy, from clumped isotope thermometry. Geology, 39(6), 571-574. https://doi.org/10.1130/g31845.1

Fiebig, J., Bajnai, D., Löffler, N., Methner, K., Krsnik, E., Mulch, A., \& Hofmann, S. (2019). Combined high-precision $\Delta 48$ and $\Delta 47$ analysis of carbonates. Chemical Geology, 522, 186-191. https://doi.org/10.1016/j.chemgeo.2019.05.019

Fiebig, J., Hofmann, S., Löffler, N., Lüdecke, T., Methner, K., \& Wacker, U. (2016). Slight pressure imbalances can affect accuracy and precision of dual inlet-based clumped isotope analysis. Isotopes in Environmental and Health Studies, 52, 12-28. https://doi.org/10.108 $0 / 10256016.2015 .1010531$

Ghosh, P., Adkins, J., Affek, H., Balta, B., Guo, W., Schauble, E. A., et al. (2006). 13C-18O bonds in carbonate minerals: A new kind of paleothermometer. Geochimica et Cosmochimica Acta, 70(6), 1439-1456. https://doi.org/10.1016/j.gca.2005.11.014

Ghosh, P., Garzione, C., \& Eiler, J. (2006). Rapid uplift of the alitplano revealed through 13C-18O bonds in paleosol carbonates. Science, 311, 511-515. https://doi.org/10.1126/science.1119365

Grauel, A.-L., Schmid, T. W., Hu, B., Bergami, C., Capotondi, L., Zhou, L., \& Bernasconi, S. M. (2013). Calibration and application of the 'clumped isotope' thermometer to foraminifera for high-resolution climate reconstructions. Geochimica et Cosmochimica Acta, 108, 125-140. https://doi.org/10.1016/j.gca.2012.12.049

Guo, W., \& Eiler, J. M. (2007). Temperatures of aqueous alteration and evidence for methane generation on the parent bodies of the CM chondrites. Geochimica et Cosmochimica Acta, 71(22), 5565-5575. https://doi.org/10.1016/j.gca.2007.07.029

Guo, W., Mosenfelder, J. L., Goddard, W. A., \& Eiler, J. M. (2009). Isotopic fractionations associated with phosphoric acid digestion of carbonate minerals: Insights from first-principles theoretical modeling and clumped isotope measurements. Geochimica et Cosmochimica Acta, 73(24), 7203-7225. https://doi.org/10.1016/j.gca.2009.05.071

He, B., Olack, G. A., \& Colman, A. S. (2012). Pressure baseline correction and high-precision CO2 clumped-isotope $\left(\Delta_{47}\right)$ measurements in bellows and micro-volume modes. Rapid Communications in Mass Spectrometry, 26(24), 2837-2853. https://doi.org/10.1002/rcm.6436

Hu, B., Radke, J., Schlüter, H.-J., Heine, F. T., Zhou, L., Bernasconi, S. M., et al. (2014). A modified procedure for gas-source isotope ratio mass spectrometry: The long-integration dual-inlet (LIDI) methodology and implications for clumped isotope measurements. Rapid Communications in Mass Spectrometry, 28(13), 1413-1425. https://doi.org/10.1002/rcm.6909

Huntington, K. W., Budd, D. A., Wernicke, B. P., \& Eiler, J. M. (2011). Use of clumped-isotope thermometry to constrain the crystallization temperature of diagenetic calcite. Journal of Sedimentary Research, 81(9), 656-669. https://doi.org/10.2110/jsr.2011.51

Huntington, K. W., Eiler, J. M., Affek, H. P., Guo, W., Bonifacie, M., Yeung, L. Y., et al. (2009). Methods and limitations of 'clumped' $\mathrm{CO} 2$ isotope $(\Delta 47)$ analysis by gas-source isotope ratio mass spectrometry. Journal of Mass Spectrometry, 44(9), 1318-1329. https://doi. $\operatorname{org} / 10.1002 / j m s .1614$

Jautzy, J. J., Savard, M. M., Dhillon, R. S., Bernasconi, S. M., Smirnoff, A., \& Smirnoff, A. (2020). Clumped isotope temperature calibration for calcite: Bridging theory and experimentation. Geochemical Perspectives Letters, 36-41. https://doi.org/10.7185/geochemlet.2021

Katz, A., Bonifacie, M., Hermoso, M., Cartigny, P., \& Calmels, D. (2017). Laboratory-grown coccoliths exhibit no vital effect in clumped isotope $(\Delta 47)$ composition on a range of geologically relevant temperatures. Geochimica et Cosmochimica Acta, 208, 335-353. https:// doi.org/10.1016/j.gca.2017.02.025

Kele, S., Breitenbach, S. F. M., Capezzuoli, E., Meckler, A. N., Ziegler, M., Millan, I. M., et al. (2015). Temperature dependence of oxygen- and clumped isotope fractionation in carbonates: A study of travertines and tufas in the $6-95^{\circ} \mathrm{C}$ temperature range. Geochimica et Cosmochimica Acta, 168, 172-192. https://doi.org/10.1016/j.gca.2015.06.032

Kelson, J. R., Huntington, K. W., Schauer, A. J., Saenger, C., \& Lechler, A. R. (2017). Toward a universal carbonate clumped isotope calibration: Diverse synthesis and preparatory methods suggest a single temperature relationship. Geochimica et Cosmochimica Acta, 197, 104-131. https://doi.org/10.1016/j.gca.2016.10.010

Kim, S.-T., Coplen, T. B., \& Horita, J. (2015). Normalization of stable isotope data for carbonate minerals: Implementation of IUPAC guidelines. Geochimica et Cosmochimica Acta, 158, 276-289. https://doi.org/10.1016/j.gca.2015.02.011

Kluge, T., John, C. M., Jourdan, A.-L., Davis, S., \& Crawshaw, J. (2015). Laboratory calibration of the calcium carbonate clumped isotope thermometer in the $25-250^{\circ} \mathrm{C}$ temperature range. Geochimica et Cosmochimica Acta, 157, 213-227. https://doi.org/10.1016/j. gca.2015.02.028

Kocken, I. J., Müller, I. A., \& Ziegler, M. (2019). Optimizing the use of carbonate standards to minimize uncertainties in clumped isotope data. Geochemistry, Geophysics, Geosystems, 20(11), 5565-5577. https://doi.org/10.1029/2019gc008545 
Müller, I. A., Fernandez, A., Radke, J., van Dijk, J., Bowen, D., Schwieters, J., \& Bernasconi, S. M. (2017). Carbonate clumped isotope analyses with the long-integration dual-inlet (LIDI) workflow: Scratching at the lower sample weight boundaries. Rapid Communications in Mass Spectrometry, 31(12), 1057-1066. https://doi.org/10.1002/rcm.7878

Müller, I. A., Rodriguez-Blanco, J. D., Storck, J.-C., do Nascimento, G. S., Bontognali, T. R. R., Vasconcelos, C., et al. (2019). Calibration of the oxygen and clumped isotope thermometers for (proto-)dolomite based on synthetic and natural carbonates. Chemical Geology, 525, 1-17. https://doi.org/10.1016/j.chemgeo.2019.07.014

Müller, I. A., Violay, M. E. S., Storck, J.-C., Fernandez, A., van Dijk, J., Madonna, C., \& Bernasconi, S. M. (2017). Clumped isotope fractionation during phosphoric acid digestion of carbonates at $70^{\circ} \mathrm{C}$. Chemical Geology, 449,1-14. https://doi.org/10.1016/j.chemgeo.2016.11.030

Mangenot, X., Gasparrini, M., Gerdes, A., Bonifacie, M., \& Rouchon, V. (2018). An emerging thermochronometer for carbonate-bearing rocks: $\Delta 47 /(\mathrm{U}-\mathrm{Pb})$. Geology, 46(12), 1067-1070. https://doi.org/10.1130/g45196.1

Massey, F. J. (1951). The Kolmogorov-Smirnov test for goodness of fit. Journal of the American Statistical Association, 46(253), 68-78. https://doi.org/10.1080/01621459.1951.10500769

Meckler, A. N., Ziegler, M., Millán, M. I., Breitenbach, S. F. M., Bernasconi, S. M., Millán, M. I., et al. (2014). Long-term performance of the Kiel carbonate device with a new correction scheme for clumped isotope measurements. Rapid Communications in Mass Spectrometry, 28(15), 1705-1715. https://doi.org/10.1002/rcm.6949

Meier-Augenstein, W., \& Schimmelmann, A. (2019). A guide for proper utilisation of stable isotope reference materials. Isotopes in Environmental and Health Studies, 55(2), 113-128. https://doi.org/10.1080/10256016.2018.1538137

Meinicke, N., Ho, S. L., Hannisdal, B., Nürnberg, D., Tripati, A., Schiebel, R., \& Meckler, A. N. (2020). A robust calibration of the clumped isotopes to temperature relationship for foraminifers. Geochimica et Cosmochimica Acta, 270, 160-183. https://doi.org/10.1016/j. gca.2019.11.022

Murray, S. T., Arienzo, M. M., \& Swart, P. K. (2016). Determining the $\Delta 47$ acid fractionation in dolomites. Geochimica et Cosmochimica Acta, 174, 42-53. https://doi.org/10.1016/j.gca.2015.10.029

Nishida, K., \& Ishimura, T. (2017). Grain-scale stable carbon and oxygen isotopic variations of the international reference calcite, IAEA603. Rapid Communications in Mass Spectrometry, 31(22), 1875-1880. https://doi.org/10.1002/rcm.7966

Passey, B. H., \& Henkes, G. A. (2012). Carbonate clumped isotope bond reordering and geospeedometry. Earth and Planetary Science Letters, 351-352, 223-236. https://doi.org/10.1016/j.epsl.2012.07.021

Passey, B. H., Levin, N. E., Cerling, T. E., BROWN, F. H., Eiler, J. M., \& Turekian, K. K. (2010). High-temperature environments of human evolution in East Africa based on bond ordering in paleosol carbonates. Proceedings of the National Academy of Sciences of the United States of America, 107(25), 11245-11249. https://doi.org/10.1073/pnas.1001824107

Peral, M., Daëron, M., Blamart, D., Bassinot, F., Dewilde, F., Smialkowski, N., et al. (2018). Updated calibration of the clumped isotope thermometer in planktonic and benthic foraminifera. Geochimica et Cosmochimica Acta, 239, 1-16. https://doi.org/10.1016/j. gca.2018.07.016

Petersen, S. V., Defliese, W. F., Saenger, C., Daëron, M., Huntington, K. W., John, C. M., et al. (2019). Effects of improved 17 O correction on interlaboratory agreement in clumped isotope calibrations, estimates of mineral-specific offsets, and temperature dependence of acid digestion fractionation. Geochemistry, Geophysics, Geosystems, 20, 3495-3519. https://doi.org/10.1029/2018gc008127

Petersen, S. V., Winkelstern, I. Z., Lohmann, K. C., \& Meyer, K. W. (2016). The effects of Porapak trap temperature on $\delta 18$ O, $\delta 13$ C, and $\Delta 47$ values in preparing samples for clumped isotope analysis. Rapid Communications in Mass Spectrometry, 30(1), 199-208. https:// doi.org/10.1002/rcm.7438

Piasecki, A., Bernasconi, S. M., Grauel, A., Hannisdal, B., Ho, S. L., Leutert, T. J., et al. (2019). Application of clumped isotope thermometry to benthic foraminifera. Geochemistry, Geophysics, Geosystems, 2018GC007961. https://doi.org/10.1029/2018GC007961

Qi, H., Moossen, H., Meijer, H. A. J., Coplen, T. B., Aerts-Bijma, A. T., Reid, L., et al. (2021). USGS44, a new high-purity calcium carbonate reference material for $\delta^{13} \mathrm{C}$ measurements. Rapid Communications in Mass Spectrometry, 35(4). https://doi.org/10.1002/rcm.9006

Schauer, A. J., Kelson, J., Saenger, C., \& Huntington, K. W. (2016). Choice of17O correction affects clumped isotope ( $\Delta 47)$ values of CO2measured with mass spectrometry. Rapid Communications in Mass Spectrometry, 30(24), 2607-2616. https://doi.org/10.1002/ rcm.7743

Schmid, T. W., \& Bernasconi, S. M. (2010). An automated method for 'clumped-isotope' measurements on small carbonate samples. Rapid Communications in Mass Spectrometry, 24(14), 1955-1963. https://doi.org/10.1002/rcm.4598

Spooner, P. T., Guo, W., Robinson, L. F., Thiagarajan, N., Hendry, K. R., Rosenheim, B. E., \& Leng, M. J. (2016). Clumped isotope composition of cold-water corals: A role for vital effects? Geochimica et Cosmochimica Acta, 179, 123-141. https://doi.org/10.1016/j.gca.2016.01.023

Swart, P. K., Murray, S. T., Staudigel, P. T., \& Hodell, D. A. (2019). Oxygen isotopic exchange between $\mathrm{CO}_{2}$ and phosphoric acid: Implications for the measurement of clumped isotopes in carbonates. Geochemistry, Geophysics, Geosystems, 20, 3730-3750. https://doi. org/10.1029/2019GC008209

Thaler, C., Katz, A., Bonifacie, M., Ménez, B., \& Ader, M. (2020). Oxygen isotope composition of waters recorded in carbonates in strong clumped and oxygen isotopic disequilibrium (2020). Biogeosciences, 17, 1-14. https://doi.org/10.5194/bg-17-1-202010.5194/ bg-17-1731-2020

van Dijk, J., Fernandez, A., Storck, J. C., White, T. S., Lever, M., Müller, I. A., et al. (2019). Experimental calibration of clumped isotopes in siderite between 8.5 and $62^{\circ} \mathrm{C}$ and its application as paleo-thermometer in paleosols. Geochimica et Cosmochimica Acta, 254, 1-20. https://doi.org/10.1016/j.gca.2019.03.018

Veillard, C. M. A., John, C. M., Krevor, S., \& Najorka, J. (2019). Rock-buffered recrystallization of Marion Plateau dolomites at low temperature evidenced by clumped isotope thermometry and X-ray diffraction analysis. Geochimica et Cosmochimica Acta, 252, 190-212 https://doi.org/10.1016/j.gca.2019.02.012

Wacker, U., Fiebig, J., \& Schoene, B. R. (2013). Clumped isotope analysis of carbonates: Comparison of two different acid digestion techniques. Rapid Communications in Mass Spectrometry, 27(14), 1631-1642. https://doi.org/10.1002/rcm.6609

Wacker, U., Fiebig, J., Tödter, J., Schöne, B. R., Bahr, A., Friedrich, O., et al. (2014). Empirical calibration of the clumped isotope paleothermometer using calcites of various origins. Geochimica et Cosmochimica Acta, 141, 127-144. https://doi.org/10.1016/j.gca.2014.06.004

Wang, Z., Schauble, E. A., \& Eiler, J. M. (2004). Equilibrium thermodynamics of multiply substituted isotopologues of molecular gases. Geochimica et Cosmochimica Acta, 68(23), 4779-4797. https://doi.org/10.1016/j.gca.2004.05.039

Werner, R. A., \& Brand, W. A. (2001). Referencing strategies and techniques in stable isotope ratio analysis. Rapid Communications in Mass Spectrometry, 15(7), 501-519. https://doi.org/10.1002/rcm.258 